\title{
EL FACTOR TIEMPO EN EL PROCESO DE PLANIFICACIÓN, CREACIÓN Y DESPLIEGUE DE LAS MISIONES DE PAZ DE LA UNIÓN EUROPEA
}

\author{
Maria JULIÀ BARCELó \\ Profesora doctora de Derecho Internacional Público y de la Unión Europea \\ Universitat Oberta de Catalunya
}

SUMARIO: 1. INTRODUCCIÓN.-2. PROCESO DE PLANIFICACIÓN Y CREACIÓN.-2.1. Diagnóstico y planificación.-2.1.1. Monitorización, análisis de la situación internacional y alerta temprana.-2.1.2. Formulación del concepto de gestión de crisis.-2.1.3. Aprobación del concepto de gestión de crisis y desarrollo de las opciones estratégicas.-2.2. Establecimiento de la misión.-2.2.1. Procedimiento de unanimidad con abstención constructiva.-2.2.2. Decisión formal de aprobación de la misión.-2.3. El factor tiempo en la planificación y establecimiento de las misiones.-2.3.1. Problemas de financiación y más.2.3.2. Creación del mecanismo ATHENA.-3. DESPLIEGUE.-3.1. Concreción de la misión y lanzamiento.-3.1.1. El concepto de las operaciones.-3.1.2. Elaboración y adopción de los acuerdos sobre el estatuto del personal/fuerza.-3.1.3. Elaboración y adopción del plan de operaciones.-3.1.4. Creación del Comité de contribuyentes y acuerdos de participación.-3.1.5. Nombramiento del jefe de misión.-3.1.6. Decisión de lanzamiento de la misión.-3.2. El factor tiempo en el lanzamiento y despliegue de las misiones.-3.2.1. La planificación como condicionante del despliegue.-3.2.2. Obstáculos internos y externos.-4. CONCLUSIONES.

\section{INTRODUCCIÓN}

La declaración de operatividad plena de la Política Europea de Seguridad y Defensa (PESD), adoptada por el Consejo Europeo de Salónica de junio de $2003^{1}$, supuso el punto de inflexión para el desarrollo «masivo» de las misio-

1 Consejo Europeo de Salónica, 19 y 20 de junio de 2003, Conclusiones de la Presidencia. Boletín UE 6-2003, pp. 16-40. 
nes de paz de la Unión Europea (UE). Para ello, la UE puso en práctica un conjunto de mecanismos institucionales previstos en los tratados o creados posteriormente por el Consejo, como el Comité Político y de Seguridad (COPS) ${ }^{2}$, el Estado Mayor de la UE (EMUE) ${ }^{3}$, el Comité Militar de la UE (CMUE) ${ }^{4}$ y el Comité para los aspectos civiles de la gestión de crisis (CIVCOM) ${ }^{5}$.

Al mismo tiempo, los Estados participantes tuvieron que poner a prueba sus capacidades civiles y militares en el desarrollo de estas operaciones. La prueba de fuego para la comprobación del funcionamiento de estos mecanismos se llevó a cabo durante el primer semestre de 2003, con la creación de la misión de policía en Bosnia-Herzegovina (MPUE) ${ }^{6}$; y de las misiones militares: CONCORDIA en la antigua república yugoslava de Macedonia $(\mathrm{ARYM})^{7}$, ARTEMIS en la RD Congo ${ }^{8}$ y, un poco después, ya en el 2004, EUFOR ALTHEA en Bosnia-Herzegovina ${ }^{9}$.

Desde el inicio de estas primeras misiones hasta las más recientes en el Chad/RCA ${ }^{10}, \operatorname{Kosovo}^{11}$, Guinea-Bissau ${ }^{12}$, Somalia ${ }^{13}$, Sudán del Sur ${ }^{14}$, Níger ${ }^{15}$, el Cuerno de África ${ }^{16}$, Mali ${ }^{17}$ y Libia ${ }^{18}$, los mecanismos institucionales y el proceso decisorio se han ido agilizando, al ritmo de las reformas de los tratados de la UE, así como al de la experiencia práctica que ha supuesto para la UE el desarrollo y ejecución de estas misiones a través de un procedimiento no reglado de creación y seguimiento posterior.

Este procedimiento está íntimamente vinculado al factor tiempo, puesto que el éxito de las misiones depende, en gran medida, de la rapidez con la que

2 Decisión 2001/78/PESC del Consejo, de 22 de enero (DO L 27/1, de 30 de enero de 2001).

3 Decisión 2001/80/PESC del Consejo, de 22 de enero (DO L 27/7, de 30 de enero de 2001).

4 Decisión 2001/79/PESC del Consejo, de 22 de enero (DO L 27/4, de 30 de enero de 2001).

5 Decisión 2000/354/PESC del Consejo, de 22 de mayo (DO L 127/1, de 27 de mayo de 2000).

6 Acción común 2002/210/PESC del Consejo, de 11 de marzo (DO L70/1, de 13 de marzo de 2002).

7 Acción común 2003/92/PESC del Consejo, de 27 de enero (DO L 34/26, de 11 de febrero de 2003).

8 Acción común 2003/423/PESC del Consejo, de 5 de junio (DO L 143/50, de 11 de junio de 2003).

9 Acción común 2004/570/PESC del Consejo, de 12 de julio (DO L 252/10, de 28 de julio de 2004).

10 EUFOR Chad/RCA (2008): Acción común 2007/677/PESC del Consejo, de 15 de octubre (DO L 279/21, de 23 de octubre de 2007).

11 EULEX Kosovo (2008): Acción común 2008/124/PESC del Consejo, de 4 de febrero (DO L 42/92, de 16 de febrero de 2008).

12 EUSSR Guinea-Bissau (2008): Acción común 2008/112/PESC del Consejo, de 12 de febrero (DO L 40/11, de 14 de febrero de 2008).

13 ATALANTA (2008): Acción común 2008/851/PESC del Consejo, de 10 de noviembre (DO L 301/33, de 12 de noviembre de 2008); y EUTM Somalia (2010): Decisión 2010/96/PESC del Consejo, de 15 de febrero (DO L 44/16, de 19 de febrero de 2010).

14 EUAVSEC Sudán del sur (2012): Decisión 2012/312/PESC del Consejo, de 18 de junio (DO L 158/17, de 19 de junio de 2012).

15 EUCAP SAHEL Níger (2012): Decisión 2012/392/PESC del Consejo, de 16 de julio (DO L 187/48, de 17 de julio de 2012).

16 EUCAP NÉSTOR (2012): Decisión 2012/398/PESC del Consejo, de 16 de julio (DO L 187/40, de 17 de julio de 2012).

17 EUTM Mali (2013): Decisión 2013/34/PESC del Consejo, de 17 de enero (DO L 14/19, de 18 de enero de 2013).

18 EUBAM Libia (2013): Decisión 2013/233/PESC del Consejo, de 22 de mayo (DO L 138/15, de 24 de mayo de 2013). 
la UE reacciona ante el desencadenamiento de una crisis internacional, sobre todo en aquellos casos en que éstas se presentan con carácter de urgencia. Asimismo, el factor tiempo ha puesto de manifiesto la existencia de diversos factores -internos y externos-, que dificultan a menudo la planificación y el despliegue de estas misiones en el tiempo debido, tal y como veremos en las secciones siguientes. Pero antes es preciso analizar el proceso que ha seguido la UE para la planificación, creación y despliegue de sus misiones. Procedimiento dotado de una gran flexibilidad ${ }^{19}$, hecho que también puede influir en una respuesta más o menos rápida ante la crisis detectada.

Así pues, el presente trabajo tiene por objeto analizar los mecanismos de creación, planificación y ejecución de las misiones de paz europeas y ponerlos en relación con el factor tiempo para determinar la efectividad y celeridad de respuesta de la UE ante situaciones de crisis que exigen una respuesta en el tiempo más breve posible. Para ello, se ha seguido una sistemática basada en el análisis de la práctica de las misiones de paz de la UE, así como de sus decisiones de creación y ejecución hasta el 2013; de las disposiciones de los tratados sobre el procedimiento de creación de las misiones de paz en el marco de la política común de seguridad y defensa (PCSD); y también del documento interno del Consejo (2003) con las sugerencias de actuación para la planificación, creación y ejecución de las misiones.

\section{PROCESO DE PLANIFICACIÓN Y CREACIÓN}

El proceso de creación de una misión de paz de la Unión, y por ende sus fases posteriores de desarrollo y finalización, no cabe dentro de lo que hoy se denomina actividad legislativa ordinaria de la Unión ${ }^{20}$. Sigue siendo, como antaño, un procedimiento específico de adopción de decisiones revestido de gran complejidad política y jurídica, algo que lo vuelve poco ágil e incierto, con frecuencia, en sus resultados finales. Su sofisticada configuración actual está condicionada por cuatro factores político-jurídicos:

a) El hecho ineludible de que la Política Exterior de Seguridad Común (PESC), política en la que se encuadran de modo genérico estas operaciones, está condicionada por su carácter eminentemente intergubernamental y, con ello, por la adopción de decisiones principalmente por unanimidad, asociadas por los Estados miembros al ejercicio de poderes duros muy vinculados a la soberanía e interés nacional.

19 El proceso de toma de decisiones estará influenciado por el entorno de la crisis, a menudo caótico. Como resultado, algunos pasos pueden ser añadidos o suprimidos, si la situación y la premura lo requieren. Igualmente, distintas versiones del mismo documento pueden ser enviadas y reenviadas entre el SEAE y los Estados miembros, que igualmente retienen en todo momento el control político. Véase con más detalle MatTELAER, A., "Decision making in the field of CSDP», en REHRL, J. y BERNHARD WEISSERTH, H. (eds.), Handbook on CSDP, en http://consilium.europa.eu/media/1823176/handbook_cs$d p$-2nd-edition_web.pdf (fecha de consulta: 11 de junio de 2013).

20 Sobre el procedimiento en general, véase GonZÁlEz SánCHEZ, E., «El proceso de toma de decisiones en el ámbito de la política exterior y de seguridad común», RDCE, 2000, núm. 8, pp. 383-415, en http:// www.cepc.es/rap/Publicaciones/Revistas/4/RDC_008_007.pdf (fecha de consulta: 18 de abril de 2009). 
b) Las experiencias previas extraídas de simulaciones y de la práctica en la creación y ejecución de las misiones de paz europeas.

c) La organización institucional extremadamente compleja de la UE. La concurrencia de distintas instituciones y órganos, con legitimidades políticas diferentes [Consejo, Comisión, COPS, CMUE, Alto Representante (AR), etc.] vuelve orgánicamente confusa la articulación de estas misiones. Es obvio que en múltiples ocasiones hay solapamiento en el ejercicio de funciones de órganos de distinta naturaleza, como entre el COREPER y el COPS ${ }^{21}$; además de la clásica tensión política, por ejemplo, entre el Consejo y la Comisión ${ }^{22}$.

d) La dificultad, en sí misma, de pergeñar operaciones multifuncionales, en contextos complejos, y con multitud de actores - dentro y fuera de la misión-, que limitan las capacidades de la Unión en la gestión rápida de las crisis. El simple hecho de que se haya distinguido, desde antiguo, entre misiones civiles del primer pilar, operaciones PESC sin carácter militar y operaciones PESD militares ${ }^{23}$, aumentaba la dificultad para la determinación de las bases jurídicas idóneas para el establecimiento de cada operación. Aunque desde las primeras operaciones realizadas en los Balcanes, la UE intentara paliar estas dificultades con la creación de una célula civil y militar que asumiera un papel destacado en la planificación y coordinación de todos los planos de acción de las misiones en Aceh y Darfur, no parece que se haya logrado aprovechar esta capacidad en el planeamiento estratégico de la reacción ante otras crisis ${ }^{24}$.

En líneas generales, éste es el proceso básico de establecimiento de las misiones de paz de la UE:

a) La decisión de llevar a cabo una misión de paz civil o militar (o híbrida), la toma el Consejo en su formación de ministros de asuntos exteriores (CAE) con la aprobación de una decisión (antes del Tratado de Lisboa, una acción común).

b) Antes de ese momento, son múltiples los actos preparatorios y los órganos implicados en su gestación, fase previa que diagnostica técnicamente sobre la situación y prefigura el plan de acción concreto.

c) Con posterioridad a su adopción, también se han acabado perfilando modos y órganos para la evaluación y seguimiento de la misión, con el fin de determinar su eficacia y adaptarla a un escenario siempre cambiante.

21 Véase Salmon, T. C. y Shepherd, A. J. K., «ESDP's Institutions», en Towards a European Army. A military power in the making?», Londres, Lynne Rienner Publishers, 2003, p. 93.

22 Véase Korski, D. y Gowan, R., "Bureaucracy and in-fighting: the Brussels problem», en Can the EU rebuild failing states? A Review of Europe's Civilian Capacities, European Council of Foreign Relations, Londres, European Council on Foreign Relations, 2009, pp. 54-55, en http://es.scribd.com/ cosmin_pacuraru/d/48052295-Can-the-EU (fecha de consulta: 11 de abril de 2013).

23 Comunicación de la Comisión al Consejo y al PE, «Financiación de operaciones de gestión civil de crisis", $\operatorname{COM(2001)~} 647$ final, de 28 de noviembre (no publicada en el Diario Oficial), pp. 4-5, en http://eur-lex.europa.eu/LexUriServ/LexUriServ.do? uri=COM:2001:0647:FIN:ES:PDF (fecha de consulta: 6 de abril de 2009).

${ }^{24}$ García PÉrez, R., "Las misiones PESD como instrumento de la política exterior de la UE», en Querol López, F. J. (dir.), Cursos de Derecho Internacional y Relaciones Internacionales de VitoriaGasteiz, 2009, Bilbao, Universidad del País Vasco, 2010, pp. 8, 39, 58 y 60. 
En julio de 2003, el Consejo adoptó la última versión de un documento interno titulado Suggestions for procedures for coherent, comprehensive EU crisis management ${ }^{25}$. En él se racionalizan de modo general las fases previas y posteriores a la aprobación de la creación de una misión de paz regional. Este documento hace visible un modelo estándar para la articulación de cualquier misión europea de gestión de crisis internacional, abierto a revisión en función de las circunstancias ${ }^{26}$. El protocolo de actuación establece diversos escenarios de gestión de crisis, incluyendo aquéllos de mayor complejidad ${ }^{27}$. Parte de la necesidad reconocida por el propio COPS de dar flexibilidad a los procedimientos internos a seguir antes del establecimiento de una misión de la actual PCSD y después de su gestación, lo que puede llevar a la omisión de algunos procesos ${ }^{28}$. La guía se basa en las disposiciones vigentes de los tratados (antes de la reforma del Tratado de Lisboa) y, al mismo tiempo, refleja los acuerdos establecidos entre la UE y la OTAN (acuerdos Berlín Plus) para la gestión de crisis conjuntas o de modo autónomo por parte de la UE, aunque utilizando las capacidades de la OTAN. También muestra otros aspectos políticos introducidos por el plan de acción política adaptado por el Consejo Europeo de Gotemburgo ${ }^{29}$.

Así, a la luz del TUE, la práctica de la Unión y la guía elaborada por el COPS, el procedimiento de establecimiento y modulación de las misiones de paz europeas conlleva siempre tres etapas: una fase previa, de análisis, diagnóstico y preparación del plan de acción para la futura misión; una fase intermedia, propiamente de creación o establecimiento de la misión; y una fase final de seguimiento, evaluación, revisión continua y cierre, en su caso, de la misma. En el momento de redactar estas líneas este procedimiento está siendo objeto de revisión con el fin de:

a) Integrar el sistema de la PCSD en el extenso Servicio Europeo de Acción Exterior (SEAE);

25 Doc. 11127/03, Council of the European Union, Suggestions for procedures for coherent, comprehensive EU crisis management, Bruselas, 3 de julio de 2003.

${ }^{26}$ KHOL, R., "Crisis Management Procedures», en NowaK, A. (ed.), Civilian crisis management: the EU way, París, Chaillot Papers, 2006, núm. 90, p. 129, en http://www.iss.europa.eu/uploads/medial cp090.pdf (fecha de consulta: 10 de abril de 2010).

27 Doc. 11127/03, op. cit., nota 25, p. iii.

28 Ibid., p. iii. El COPS menciona entre estos procesos que pueden ser omitidos por la UE, aquéllos relativos a las recomendaciones sobre la identificación y/o nombramiento de un cuartel general de la operación y de un comandante de la operación, puesto que estas recomendaciones pueden realizarse en cualquier momento del proceso y cuando sea considerado necesario. Además, muchos de estos procedimientos, como el desarrollo del concepto de gestión de crisis, son de naturaleza repetitiva.

29 Este programa se basaba en el desarrollo de las capacidades, estructuras y procedimientos de la UE, con el fin de mejorar su aptitud para asumir toda la gama de tareas de prevención de conflictos y de gestión de crisis utilizando medios civiles y militares. Los principales puntos de este plan hacen referencia al mando y control de las operaciones, la formación y los criterios de selección de personal y la interoperabilidad. Todos estos puntos deben servir para completar las operaciones internacionales de policía que tienen lugar en el marco de la ONU o la OSCE y evitar de este modo duplicaciones innecesarias. Véase Consejo Europeo de Gotemburgo, 15 y 16 de junio de 2001, Conclusiones de la Presidencia (28/43), Boletín UE 6-2001. 
b) Acelerar el proceso de planificación, reduciendo el número de decisiones políticas requeridas para lanzar una nueva misión, al mismo tiempo que asegurar la debida supervisión y control político de los Estados miembros;

c) Armonizar los procesos civiles y militares;

d) Estandarizar la documentación de planificación a través del uso de nuevos patrones; y finalmente,

e) Acercar los niveles operacional y estratégico introduciendo un ejercicio de percepción de fuerza; así como,

f) Involucrar antes al equipo de planificación operacional en todo el proceso $^{30}$.

En el plano normativo, hasta diciembre de 2009, la creación, modificación y cierre de las misiones de la UE se habían venido articulando a través de dos tipos de actos, las denominadas acciones comunes y las decisiones comunes $^{31}$. Ahora ambas se etiquetan de modo genérico como decisiones (art. 25 del TUE).

\subsection{Diagnóstico y planificación ${ }^{32}$}

Las actividades de la Unión en la fase previa al establecimiento de una misión de paz europea son muy variadas. En lo esencial, podemos distinguir dos actividades sucesivas:

a) El funcionamiento de mecanismos propios de monitorización y análisis de la situación internacional y alerta temprana.

b) En el caso de irrupción de una crisis internacional, la formulación del concepto de gestión de crisis y la gestación de la propuesta de estrategia concreta para su adopción por el Consejo.

En esta fase concurre principalmente el ejercicio de funciones por parte del Centro de Análisis de Inteligencia de la UE (EU INTCEN), el antiguo SITCEN ${ }^{33}$; el COPS; el AR y, en su caso, el Representante especial de la UE (REUE). Este último, en el caso de las misiones militares, ha ejercido un papel importante en la región de los Grandes Lagos, en la ARYM y en Bosnia, desarrollando una notable función de diálogo con las autoridades nacionales

30 El 1 de diciembre de 2011, el CAE invitó a la AR a proponer una revisión de los procedimientos de gestión de crisis. El documento de 2003 ha perdido parte de su relevancia atendiendo a los cambios en la arquitectura institucional después de la entrada en vigor del Tratado de Lisboa y a la evolución en la dirección de la PCSD. En respuesta, la AR constituyó un grupo de trabajo liderado por Yves de Kerrmabon, ex comandante y primer jefe de misión de EULEX Kosovo, cuyas propuestas se esperaban para el 2013. Véase MATTELAER, A., «Reviewing the EU's Crisis management Procedures», Institute for European Studies, 2012, núm. 4, en http://www.ies.be/files/2012-04_AM_final.pdf (fecha de consulta: 5 de junio de 2013).

31 Antiguos arts. 14 y 23 del TUE.

32 Véase el Doc. 11127/03, «Routine phase», op. cit., nota 25, pp. 5-6.

33 El Centro de Satélites de la UE continúa sus actividades, desde su transferencia al SEAE en enero de 2011, con el nombre de EU INTCEN (Centro de Análisis de Inteligencia de la UE). Véase BERNHARD WEISSERTH, H., «The crisis management structures», en op. cit., nota 19, p. 44. 
y locales, e informando en todo momento al AR sobre la evolución de la situación ${ }^{34}$. También la Comisión, el Centro de Satélites - junto con los servicios de inteligencia de los Estados miembros-, el EMUE, el CMUE y los grupos de trabajo del Consejo, siguen la evolución de las diferentes crisis que surgen en el contexto internacional.

\subsubsection{Monitorización, análisis de la situación internacional y alerta temprana}

En el marco de la prevención y gestión de crisis, la alerta temprana favorece la actuación rápida de la Unión y la articulación de mecanismos de prevención de conflictos antes del agravamiento de la situación identificada como potencialmente peligrosa para la paz internacional. Así, la UE ha cristalizado mecanismos propios de prevención de conflictos en el marco de la PESC $^{35}$.

El EU INTCEN es una de las piezas clave en ese proceso de obtención y análisis de la información pertinente, ahora integrado en el SEAE ${ }^{36}$. Su principal función es el seguimiento de la situación internacional y la elaboración de análisis conjuntos de la situación exterior para el apoyo de cualquier decisión que pueda querer tomar la UE. Estos análisis sirven en un primer momento para facilitar la alerta temprana sobre la emergencia de cualquier crisis, aunque luego continúe como mecanismo de información permanente en apoyo de operaciones de la Unión que ya están en marcha. El EU INTCEN lidera estas valoraciones que están a disposición del COPS, del AR y del Consejo, y produce análisis estratégicos de las amenazas con base en la inteligencia ofrecida por los servicios de inteligencia de los países miembros y también según la información ofrecida por la EUROPOL.

Si fracasa la prevención de un conflicto y se produce el estallido de una crisis, la recogida de información previa es uno de los elementos determinantes para el correcto proceder posterior de la Unión. El COPS se ocupa del conjunto de funciones definidas en el art. 38 del TUE, siendo el encargado de seguir la situación internacional en los ámbitos correspondientes a la PESC. A través de este seguimiento contribuye a definir esta política por medio de:

\footnotetext{
34 Acosta SÁnchez, M. A., La Política Europea de Seguridad y Defensa y la Gestión de Crisis Internacionales: Las operaciones Petersberg, Madrid, Dykinson, 2008, p. 177.

35 Esta prevención, engloba diferentes pilares: a) abordando el nexo entre seguridad y desarrollo en los países frágiles; $b$ ) mejorando el enlace de alerta temprana con la actuación temprana; $c$ ) fortaleciendo la creación de las capacidades de los Estados miembros; d) aumentando la cooperación con los socios internacionales, incluidos los agentes no estatales, y e) mediante el recurso, por parte de la Comisión, al instrumento de estabilidad para apoyar los objetivos de la PESC. Véase Consejo de la Unión Europea, «Informe anual del Consejo al Parlamento Europeo sobre los principales aspectos y las opciones fundamentales de la PESC», 2007, p. 80, en http://www.consilium.europa.eu/uedocs/cmsUpload/ES_PESC.pdf (fecha de consulta: 18 de marzo de 2008).

36 Véase Decisión 2010/427/UE del Consejo, de 26 de julio, por la que se establece la organización y el funcionamiento del SEAE (DO L 201/30, de 3 de agosto de 2010).
} 
«[...] la emisión de dictámenes dirigidos al Consejo, bien a instancia de éste, del Alto Representante de la Unión para Asuntos Exteriores y Política de Seguridad o por propia iniciativa».

Una vez detectada la crisis, el COPS se encarga de preparar la propuesta de respuesta que debe dar la UE ante su aparición. Así, propondrá los objetivos políticos a seguir por parte de la Unión ante la crisis, y examinará las posiciones disponibles para contribuir a la solución de la misma. Aunque no tiene un poder formal de toma de decisiones, el COPS es determinante, pues recomienda al Consejo la línea de acción a seguir ${ }^{37}$. En este sentido:

a) Examina las opciones posibles de respuesta de la UE, en el marco institucional único, sin perjuicio de los procedimientos de decisión y de aplicación propias de cada marco jurídico en el que se regulan las relaciones exteriores de la UE (el TUE o el TFUE, antes separados por pilares).

b) Propone al Consejo los objetivos políticos que deberá perseguir la Unión y recomienda un conjunto coherente de acciones que ayuden a resolver la crisis. En este sentido, el COPS podrá emitir un dictamen recomendando al Consejo la adopción de una decisión.

c) Vigila también la aplicación de las medidas acordadas y evalúa sus efectos, todo ello sin perjuicio de las competencias de la Comisión, que deberá informar al COPS de las medidas que tome o piense tomar. Igualmente, los Estados miembros también deberán comunicarle las medidas que hayan tomado o piensen tomar en el plano nacional.

d) Finalmente, también desempeña un papel esencial en la intensificación de las consultas, sobre todo con la OTAN y con los terceros Estados afectados.

Así pues, en esta fase previa de monitorización de la situación internacional los Estados miembros y la Comisión se intercambian información dentro del COPS, así como dentro de los grupos de trabajo del Consejo. También el CMUE se constituye en el foro para las consultas militares y la cooperación entre los Estados miembros en el marco de la prevención y la gestión de crisis. Es este Comité el que calcula los riesgos de potenciales crisis y proporciona consejos militares y dirige recomendaciones al COPS, a petición previa o por propia iniciativa. Igualmente, el CIVCOM proporciona información, formula recomendaciones y da consejos sobre los aspectos civiles de la gestión de crisis al COPS y a otros grupos del Consejo. Del mismo modo, el CIVCOM puede proporcionar consejo y recomendaciones, en caso necesario, sobre los aspectos civiles relacionados con potenciales crisis.

Paralelamente, en caso de ser necesario por la naturaleza de la crisis, la UE inicia consultas y coopera con la OTAN. Antes de la creación del SEAE

\footnotetext{
37 Missiroli, A., "Cómo funciona la PESD», en Gnesotto, N. (ed.), Política de Seguridad y Defensa de la Unión europea. Los cinco primeros años (1999-2004), París, EU ISS, 2004, p. 68. Tal y como explica este autor, la toma de decisiones políticas o estratégicas depende en realidad del Consejo de Asuntos Generales y Relaciones Exteriores, mientras que para los aspectos administrativos y financieros de la PESC/PCSD el órgano principal sigue siendo el COREPER.
} 
—que ha absorbido estas funciones-, a través de la antigua Presidencia, el AR y la Secretaría del Consejo, incluido el EMUE, actuando bajo la dirección del CMUE, se mantenían los contactos regulares con la OTAN. La UE también procede a consultar con los Estados europeos no miembros de la OTAN y otros terceros Estados. Los contactos y la cooperación, en caso necesario, son mantenidos también con la ONU y otras organizaciones regionales, así como con ONG.

Asimismo, en esta fase inicial se inicia la coordinación con el fin de avanzar en la planificación de la futura misión. Coordinación que es conducida por el EMUE para los aspectos militares, la Unidad de policía para los aspectos policiales y la Secretaría del Consejo y la Comisión para otros aspectos civiles. Los Estados miembros proporcionan el Mecanismo de coordinación para los aspectos civiles e interactúan con los servicios de la Comisión, con la información sobre las capacidades disponibles de los Estados miembros para la gestión civil de crisis, incluido su estado de preparación o despliegue y las contribuciones bilaterales.

Así pues, en esta fase inicial o de rutina, tanto la antigua Presidencia, como el SG/AR, los Estados miembros y la Comisión llevaban a cabo actividades de información ${ }^{38}$, hoy en día canalizadas a través del SEAE.

\subsubsection{Formulación del concepto de gestión de crisis}

En ese momento inicial continúa y se intensifica la recogida e intercambio de información de los servicios de inteligencia, procedente de los Estados miembros y de la Comisión, pero no sólo a nivel interno, sino también de otras organizaciones internacionales, como la OTAN, la ONU o la OSCE. La Comisión informa al COPS de las medidas emprendidas o bajo preparación, y de la posibilidad de utilizar otros instrumentos; del mismo modo, los Estados miembros también le informan sobre las medidas adoptadas con base en las normas nacionales. En caso necesario, el COPS identifica las áreas específicas o temas sobre los que se requiere información adicional. En este sentido, el COPS debería tener acceso a toda la información necesaria procedente tanto de otras organizaciones internacionales, como de todas las propuestas e iniciativas relacionadas con la crisis. Asimismo, el EU INTCEN recopila toda la información disponible, la procesa e informa sobre la situación al AR y a los órganos competentes para la gestión de crisis, en particular al COPS y al CMUE.

El COPS procede a poner en discusión la situación de crisis detectada a la luz de todos los «inputs» recibidos, con el fin de desarrollar un concepto político común de la crisis y proporcionar una mayor guía política. Así, puede también requerir información a los jefes de misión diplomáticos. Y de acuerdo con los cálculos políticos preliminares, puede requerir información específica del EU INTCEN, de la Comisión y de los Estados miembros, así

38 Doc. $11127 / 03$, «Routine phase», op. cit., nota 25, pp. 5-6. 
como de otros órganos competentes para que le proporcionen información adicional. Además, en este momento el AR puede aportar su dirección operativa al EU INTCEN, con el fin de monitorizar de cerca la crisis identificada. Igualmente, el COPS puede acordar que se lleve a cabo una misión conjunta de exploración o recogida de datos, por parte de la Secretaría General del Consejo y de la Comisión en la región y, al mismo tiempo, empezar a considerar la posibilidad de nombrar a un REUE ${ }^{39}$.

Así, la realización de las primeras misiones de la UE en los Balcanes contó con un grupo de planeamiento. En el caso concreto de la misión EUPOL PRÓXIMA en Macedonia (2003), se creó el grupo de planeamiento a cargo del jefe de la misión, que ejercía al mismo tiempo de jefe del grupo de planeamiento, con el objeto de evaluar los riesgos que comportaría la realización de la misión. En este caso, el grupo de planeamiento colaboró estrechamente con la OSCE, ya presente en la zona ${ }^{40}$.

La misión EUPOL Afganistán (2007) nos proporciona más datos sobre este tipo de actuación, en el marco de una situación de gran inestabilidad e inseguridad. Solicitada la ayuda por parte de las autoridades afganas, la UE, antes de crear la misión de policía, envió en julio de 2006 una misión de carácter exploratorio, con la participación de los Estados miembros, para evaluar la situación. En octubre de ese mismo año, la misión presentó un informe al COPS, con el análisis efectuado, además de recomendaciones sobre cómo reforzar la contribución de la UE en este sector y lograr un impacto estratégico. El informe recomendaba específicamente que la UE considerara contribuir al apoyo del sector de la policía mediante una misión de policía y que enviase una misión de investigación para estudiar la viabilidad de la misma ${ }^{41}$.

Es en este momento, antes de la puesta en marcha de la misión, cuando las instituciones de la UE y los Estados miembros inician la planificación, a partir de la información que emana de los órganos que han monitorizado y seguido la situación de crisis, en la que se intenta evaluar los riesgos a los que puede enfrentarse la futura misión.

Esta fase exploratoria es seguida de la definición del concepto de gestión de crisis. Es decir, de la determinación de los objetivos político-militares, estratégicos y políticos de la misión, la estrategia de inicio y fin, las restricciones y limitaciones, los riesgos, las consideraciones sobre su duración, las tareas y la cadena de mando. Este concepto ofrece las bases para crear la decisión (antigua acción común) que proveerá el marco legal para la creación de la misión ${ }^{42}$. Para su elaboración, la actividad de inteligencia del EU INTCEN,

\footnotetext{
39 Doc. 11127/03, «Phase 2 Crisis build-up/Elaboration of the draft CMC», op. cit., nota 25, pp. 7-8.

${ }^{40}$ Véase el art. 2 de la Acción común 2003/681/PESC del Consejo, de 29 de septiembre (DO L 249/66, de 1 de octubre de 2003).

${ }_{41}$ Véase el antecedente (4) de la Acción común 2007/369/PESC del Consejo, de 30 de mayo (DO L 139/33, de 31 de mayo de 2007).

42 Simón, L., "Command and control? Planning for EU military operations», EU ISS, Occasional paper, 2010, núm. 81, p. 12, en http://www.iss.europa.eu/uploads/media/Planning_for_EU_military_operations.pdf (fecha de consulta: 13 de abril de 2011).
} 
junto con los intercambios de puntos de vista entre la Comisión, el AR y el COPS, es esencial. Al COPS le corresponde su articulación.

Si en esta fase el COPS considera apropiada una acción de la UE puede iniciar el desarrollo del proyecto concreto del concepto de gestión de crisis. La elaboración de este proyecto la lleva a cabo «el equipo de coordinación de respuesta a una crisis». Este tipo de equipos son los instrumentos ad hoc para llevar a cabo la coordinación entre los distintos servicios de la Unión y tienen una composición flexible, puesto que están formados por representantes de: a) la Comisión, b) el gabinete del AR, c) el EMUE, d) la Unidad de policía, e) la Unidad política,f) el Servicio jurídico del Consejo, y g) el EU INTCEN ${ }^{43}$.

El AR instruye a los servicios más relevantes para participar en el equipo. De modo general, sin embargo, el análisis de las opciones militares y de policía es llevado a cabo por el EMUE y la Unidad de policía, respectivamente. Con respecto a otros instrumentos civiles, la planificación se lleva a cabo a través de las informaciones proporcionadas por los Estados miembros al «Mecanismo de coordinación de los aspectos civiles de una gestión de crisis». En esta fase el EMUE puede buscar el cuartel general apropiado para planificar y dirigir la futura operación militar. También puede consultar con los Estados miembros y recomendar un determinado cuartel general al COPS.

Ahora bien, debemos tener presente que en noviembre de 2008 una iniciativa franco-británica posibilitaría la creación de la Dirección de Gestión de Crisis y Planificación Estratégica (DGCP), que desde 2009 ha asumido la responsabilidad de la planificación a escala política y estratégica, tanto de las misiones militares como de las no militares de la $\mathrm{UE}^{44}$. A pesar de que todavía es poco clara su organización, esta Dirección reúne en un solo departamento todas las capacidades estratégicas de planificación de la UE, hasta ahora dispersas en la estructura del Consejo (Dirección General 8, Dirección General 9, célula civil-militar, etc.) ${ }^{45}$. Así pues, es esta Dirección la que debe ofrecer actualmente una planificación exhaustiva de las misiones de la PCSD al nivel estratégico, y es la responsable de elaborar el concepto de gestión de crisis $^{46}$. Así ha sucedido en las recientes misiones EUAVSEC Sudán del sur (2012) para la que desarrolló el concepto para garantizar la seguridad en el aeropuerto de Juba ${ }^{47}$; EUCAP NÉSTOR-Cuerno de África (2012) para

43 Doc. 11127/03, "Council Secretariat/Commission outline paper on the CRCT», en el anexo 2 del anexo, op. cit., nota 25, pp. 31-34.

${ }_{44}$ Fuente: Grupo PPE en el Parlamento Europeo, «La Europa de la defensa. Pequeña guía de la PCSD 2010», julio de 2010, en http://stream.eppgroup.eu/Activities/docs/year2010/defence_europe-es.pdf (fecha de consulta: 17 de mayo de 2011).

45 Simón, L., op. cit., nota 42, p. 25.

46 Simón, L., "La Presidencia española y la PESD: es hora de tomarse en serio la capacidad de la Unión para la planificación y la dirección de las operaciones militares», Real Instituto Elcano, ARI, 2010, núm. 55, p. 7, en http://www.realinstitutoelcano.org/wps/wcm/connect/1194d68041db0058bfabbf 7ab4baf5a3/ARI552010_Simon_Presidencia_espanola_PESD.pdf?MOD=AJPERES\&CACHEID=1194d68 041db0058bfabbf7ab4baf5a3 (fecha de consulta: 12 de mayo de 2011). Véase también BERNHARD WEISSERTH, H., op. cit., nota 33, p. 42.

47 Antecedente (4) de la Decisión 2012/312/PESC, op. cit., nota 14. 
la que creó el concepto para desarrollar las capacidades marítimas regionales ${ }^{48}$; EUCAP SAHEL Níger (2012) para la que desarrolló el concepto de una eventual misión civil de la PCSD en el Sahel ${ }^{49}$; EUTM Mali (2013) para la que desarrolló el concepto relativo a una eventual misión de formación militar en Mali ${ }^{50}$; y EUBAM Libia (2013) para el que desarrolló un concepto de gestión de crisis para una eventual misión civil de la PCSD en Libia ${ }^{51}$.

\subsubsection{Aprobación del concepto de gestión de crisis y desarrollo de las opciones estratégicas ${ }^{52}$}

El concepto de gestión de crisis contiene un análisis de los hechos, situaciones, intereses y objetivos involucrados. A través de este concepto se establece la evaluación de las distintas opciones de respuesta de la UE ${ }^{53}$. El proyecto de documento con este concepto es presentado por el AR al COPS, quien recibirá la opinión del EMUE y del CIVCOM sobre los aspectos civiles y militares, respectivamente, fijados en este documento. En este proceso, el COPS incluirá su opinión al final del proyecto de documento y lo transmitirá al Consejo, iniciándose de este modo la tercera fase de este proceso.

Esta fase se inicia con la aprobación por parte del Consejo, sobre la base de la recomendación del COPS, del concepto de gestión de crisis. Este concepto es aprobado antes de la adopción de la decisión de creación de la misión. Sirva de ejemplo de concepto de gestión de crisis el elaborado para la misión EUPOL Afganistán (2007). En diciembre de 2006, la UE envió a Afganistán una misión de investigación, con base en cuyas conclusiones, de 12 de febrero de 2007, el antiguo Consejo de Asuntos Generales y Relaciones Exteriores (CAGRE) aprobó el concepto de gestión de crisis (CMC) para la misión, en el siguiente sentido:

«La misión se esforzará por establecer una fuerza de policía afgana en régimen de responsabilización local, que respete los derechos humanos y opere en el marco del Estado de Derecho. La misión deberá basarse en los esfuerzos ya en curso y adoptar un planteamiento global y estratégico en consonancia con el CMC. Para ello la misión deberá abordar cuestiones tales como la reforma de la policía a nivel central, regional y provincial, según corresponda» ${ }^{54}$.

Asimismo, el concepto de gestión de crisis distingue entre elementos civiles y militares. Con relación a los elementos civiles, la elaboración de los elementos del proyecto que se presenta al Consejo para establecer las opciones

\footnotetext{
48 Antecedente (3) de la Decisión 2012/389/PESC, op. cit., nota 16.

49 Antecedente (2) de la Decisión 2012/392/PESC, op. cit., nota 15.

50 Antecedente (6) de la Decisión 2013/34/PESC, op. cit., nota 17.

51 Antecedente (3) de la Decisión 2013/233/PESC, op. cit., nota 18.

52 Véase el Doc. 11127/03, "Approval of the crisis management concept and the development of strategic options», op. cit., nota 25, pp. 12-15.

53 Ibid. Véase un modelo de Concepto de gestión de crisis en el anexo 3 del anexo, pp. 36-39.

54 Véase el Doc. 6039/07, Asuntos Generales y Relaciones Exteriores, Sesión núm. 2780, Bruselas, 12 de febrero de 2007.
} 
estratégicas de policía y las opciones estratégicas civiles recae principalmente en la Unidad de policía y el mecanismo de coordinación para los aspectos civiles de la gestión de crisis. Estos órganos pueden recibir asistencia por parte del CIVCOM y de la Comisión (así como de expertos nacionales). A través del mecanismo de coordinación, los Estados miembros indican también su intención de contribuir o no a la posible operación. Para las operaciones de policía, la Unidad de policía incluye recomendaciones en relación con el jefe de policía de la misión y el cuartel general de operaciones. Del mismo modo que para el CMC, el borrador de las opciones militares estratégicas y de las opciones estratégicas de policía y las opciones estratégicas civiles será adoptado por el COPS después de recibir el consejo del CMUE (en relación con las opciones militares estratégicas) y del CIVCOM (en relación con las opciones estratégicas de policía y las opciones estratégicas civiles). El COPS someterá al Consejo su aprobación final.

Respecto a los elementos militares, el COPS requerirá al CMUE para que emita una directiva de opciones militares estratégicas al EMUE, quien se encargará de desarrollar y priorizar las opciones militares estratégicas. El EMUE también puede recibir asistencia del cuartel general designado para la operación. Por otro lado, los Estados miembros y los terceros Estados interesados también aportan al EMUE indicaciones preliminares sobre su intención de contribuir o no a la posible operación ${ }^{55}$.

La misión militar EUTM Somalia (2010) contiene la información suficiente para seguir el orden cronológico en la actuación del Consejo, encaminada a la aprobación del concepto de gestión de crisis y al desarrollo de las opciones estratégicas de esta fase. Así, el 17 de noviembre de 2009, el Consejo aprobó un concepto de gestión de crisis, en relación con una posible misión europea de seguridad y defensa con el fin de contribuir a la formación de las fuerzas de seguridad del gobierno federal de transición de Somalia. Al mismo tiempo, pidió nuevos trabajos de planificación, lo que motivó que el COPS creara un órgano de planificación ${ }^{56}$. Con posterioridad, el 8 de

55 El Consejo Europeo de Niza aprobó un documento que regula los dispositivos permanentes de consulta y participación de terceros países en la gestión de crisis. En este documento se establecían dos supuestos: a) Las consultas fuera del periodo de crisis: se realizan con carácter periódico. En este sentido, cada país tercero puede designar a un representante para garantizar el seguimiento de la PCSD y ser interlocutor del COPS. Además, y con el fin de facilitar la asociación de terceros Estados a las actividades militares de la UE, éstos podrán designar a un oficial acreditado ante el Estado mayor que servirá de punto de contacto. Y b) Las consultas en periodo de crisis: durante este periodo de estudio de una hipotética operación militar de gestión de crisis, las consultas tendrán el objetivo de asegurar que los países terceros puedan contribuir a la operación y estén informados de las intenciones de la UE, en especial de las opciones militares proyectadas. Tras la decisión formal del Consejo sobre las opciones militares y el concepto de operación, se invitará formalmente a los países terceros a participar. Cuando para la operación se recurra a los medios y capacidades de la OTAN, los miembros de la OTAN no miembros de la UE podrán decidir su participación sin necesidad de ser invitados. Véase Consejo Europeo de Niza, 7, 8 y 9 de diciembre de 2000, Conclusiones de la Presidencia, anexo VI, Dispositivos relativos a los Estados europeos miembros de la OTAN no pertenecientes a la UE y otros países que son candidatos a la adhesión a la UE, Boletín UE 12-2000, pp. 1-36.

56 Antecedente (4) de la Decisión 2010/96/PESC, op. cit., nota 13. 
diciembre de 2009, el Consejo seleccionó una opción militar estratégica para la posible misión militar. Esta opción supone, o bien llevar a cabo una operación militar de carácter autónomo, sin utilizar las capacidades y medios de la OTAN, o bien una operación militar realizada con los recursos de la OTAN puestos a disposición de la Unión. En este caso, la opción escogida fue de carácter autónomo.

En este momento anterior a la aprobación de la decisión, el Consejo también puede adoptar otro tipo de medidas, como, por ejemplo, nombrar a un REUE si la operación lo requiere, o anotar la disponibilidad de un cuartel general operacional para una posible operación militar. Además, el COPS puede identificar posibles comandantes para la operación. También establecerá el borrador de las opciones estratégicas a seguir, ya sean militares o de policía, incluida la propuesta de la cadena de mando ${ }^{57}$.

\subsection{Establecimiento de la misión}

La creación de una operación en el marco de la PCSD se inicia cuando el CAE decide, por unanimidad, llevar a cabo una misión de estas características a partir de una decisión que contiene una acción en común. Ya hemos visto cómo, de modo previo a esta decisión, el COPS, asistido por el CIVCOM y/o el CMUE, elabora sus recomendaciones técnicas, considera las propuestas de operaciones civiles o militares y desarrolla estrategias para el despliegue de la operación. El COPS, así, ostenta un claro poder de orientación estratégica de la propuesta de operación, ahora asistido por el AR desde la entrada en vigor del Tratado de Lisboa, puesto que es este último, bajo la autoridad del Consejo y en contacto permanente y estrecho con el COPS, quien se hará cargo de la coordinación de los aspectos civiles y militares de las misiones de paz (art. 43.2 del TUE).

El procedimiento de adopción de los actos en el marco de la PESC, previsto en el nuevo art. 31 del TUE, sigue siendo el mismo aunque con una participación mayor del AR, en tanto que preside las reuniones del Consejo de Asuntos Exteriores (art. 18.3 del TUE). Las actuales misiones de paz europeas se siguen aprobando por unanimidad, sobre la que se proyecta el mecanismo de flexibilidad de la abstención constructiva como modo para liberar a un Estado miembro de participar en la misión, sin que por ello impida su creación.

\subsubsection{Procedimiento de unanimidad con abstención constructiva}

La base jurídica específica para la aprobación de una decisión de creación de una misión de paz de la UE se recoge en el art. 42 del TUE. Fundamentando su actuación sobre la base de este artículo:

57 Doc. 11127/03, «Phase 4 Formal decision to take action, development of planning documents», op. cit., nota 25 , p. 17. 
«4. El Consejo adoptará por unanimidad, a propuesta del Alto Representante de la Unión para Asuntos Exteriores y Política de Seguridad o a iniciativa de un Estado miembro, las decisiones relativas a la política común de seguridad y defensa, incluidas las relativas al inicio de una misión contemplada en el presente artículo. El Alto Representante podrá proponer que se recurra a medios nacionales y a los instrumentos de la Unión, en su caso conjuntamente con la Comisión».

Tal y como recoge el apartado 1 del art. 31 del TUE, la regla general para aprobar una decisión de creación de una misión de paz es la unanimidad:

«El Consejo Europeo y el Consejo adoptarán por unanimidad las decisiones de que trata el presente capítulo, salvo en los casos en que el presente capítulo disponga otra cosa. Se excluye la adopción de actos legislativos».

En el mismo apartado se especifica que, en aquellos casos en los que un Estado miembro se abstenga en la votación, podrá acompañar la misma de una declaración formal por la que acepta que su posición no bloquee la adopción de la decisión propuesta. Se trata de un mecanismo que tiene cierta analogía con la práctica del Consejo de Seguridad de la ONU desde los años sesenta, por la que se alteró la regla del art. 27.3 de la Carta. En este caso, se detallan con claridad las consecuencias jurídicas de la abstención constructiva:

a) Para la UE la abstención constructiva no impide la adopción de la decisión de llevar a cabo una acción por parte del Consejo y que ésta sea vinculante para la Unión y los Estados que se manifiesten a favor.

b) En la esfera del Estado que se abstiene, se le excluye de tener la obligación de dar aplicación a la decisión, aunque pende sobre él una obligación accesoria. Tal y como especifica el párr. 2 de la misma disposición:

«[... en aras de la solidaridad mutua, este Estado se abstendrá de llevar a cabo aquellas acciones que pudieran impedir o poner trabas a la acción de la UE».

La finalidad de este mecanismo radica en facilitar la flexibilidad en la entrada en vigor de parte del Derecho de la UE entre los Estados de la Unión, al permitir «una aplicación no uniforme» de las obligaciones generadas en el ámbito de la PESC ${ }^{58}$. El procedimiento de abstención constructiva tiene una limitación. Si se abstienen un tercio de los Estados miembros, que reúnan como mínimo un tercio de la población de la Unión, la decisión no podrá ser adoptada $^{59}$.

Luis Norberto González Alonso ha señalado que el mecanismo de la abstención constructiva tiene el riesgo de favorecer la creación de alguna situación «esperpéntica» ${ }^{60}$. Permite a un Estado fácilmente desvincularse de

58 Urrea Corres, M., «La toma de decisiones en el ámbito de la PESC: la abstención constructiva como alternativa a la unanimidad», REDUR, 2002, núm. 0, p. 154. En el mismo sentido, MARTín MARTÍNEZ, M. a M., "La acción exterior de la Unión Europea», en ALCAIDE FERNÁNDEZ, J. y CASAdo RAIGóN, R. (coords.) Curso de Derecho de la Unión Europea, 1. ${ }^{\mathrm{a}}$ ed., Madrid, Tecnos, 2011, p. 407.

59 Urrea Corres, M., op. cit., nota 58, p. 155.

${ }^{60}$ González Alonso, L. N., "La política europea de seguridad y defensa después de Niza», RDCE, 2001, núm. 9, pp. 227-228. 
una decisión del Consejo, sin que ello impida que se impute en su conjunto a la Unión y, al hacerlo así, no tiene que soportar ninguna carga financiera derivada de la operación. Pero quizá los problemas mayores no sean éstos, sino la disociación de las opciones de acción exterior de la UE, con respecto a la posición en la misma materia de algunos Estados, que no queda suficientemente paliada por la obligación accesoria de no obstrucción. Una de las aplicaciones singulares más sorprendentes de este procedimiento nos ayuda a ver el orden de este problema. Se trata del caso EULEX Kosovo (2008).

La aprobación de esta misión estuvo condicionada por las divisiones que provocó en el seno de la Unión la Declaración Unilateral de Independencia de Kosovo. Su creación se facilitó con la abstención de Chipre, Grecia, Eslovaquia, España y Rumania, países que se han opuesto persistentemente al reconocimiento de la independencia de Kosovo ${ }^{61}$. La abstención constructiva permitió crear esta misión sobre la que varios miembros no querían asumir ninguna responsabilidad, generando un desapego evidente hacia la actuación política de la Unión, más allá de que estos Estados miembros se abstengan además de contribuir con personal a la misión. Por qué no quiso asumir España el coste de un voto negativo, en lugar de facilitar la creación de la misión con su abstención, es una pregunta que encuentra su respuesta en las complejidades de la diplomacia europea, y la pérdida de relevancia de España en la política internacional. La UE entró en conflicto también con la ONU, en la medida en que desde allí no se había alterado el mandato de la misión UNMIK. Rusia y Serbia bloquearon el traspaso de poderes de la UNMIK a EULEX Kosovo y a las autoridades locales, lo que hizo imposible que esta misión fuera completamente desplegada el 15 de junio de 2008, tal y como se había planeado inicialmente ${ }^{62}$.

Obviamente, en este proceso intergubernamental de decisión y posterior seguimiento de una misión de paz, el Parlamento Europeo tiene un papel menos relevante, al contenerse el conjunto de la acción en el marco de la PESC. $\mathrm{El}$ art. 36 del TUE le continúa otorgando un papel únicamente consultivo.

\subsubsection{Decisión formal de aprobación de la misión}

Fundamentado en el art. 42 del TUE, el Consejo procede primero a la adopción formal de una decisión, por la que autoriza la creación de la misión de paz en el marco de la PCSD, y solicita a los Estados miembros que colaboren en ella. El art. 28 del TUE (antiguo art. 14), ha sido la base jurídica habilitadora para la creación de una decisión que regula el establecimiento de una misión de carácter militar o civil. El contenido de la decisión es vinculante para los Estados miembros, tanto en las posiciones que adopten

61 Editorial Comments, "And the meantime... Kosovo...», CMLR, 2009, núm. 46, p. 378.

62 Blockmans, S. y Wessel, R. A., "The European Union and crisis management: Will the Lisbon Treaty make the EU more effective?», Journal of Conflict \& Security Law, vol. 14, 2009, núm. 2, pp. 277-278. 
en el futuro como en el desarrollo de su acción. El carácter vinculante de la decisión de la acción va unido a la obligación de los Estados miembros de informar al Consejo sobre los planes o las acciones nacionales que se considera necesario emprender para su aplicación ${ }^{63}$. No se trata todavía, por tanto, de la constitución como tal de la misión que requiere de otras decisiones de ejecución posteriores. Esta decisión aprueba la configuración jurídica básica o primaria de una misión de la UE, antes de su despliegue sobre el teatro de operaciones.

Las decisiones por las que se establece una acción que va a realizar la Unión eran definidas por el antiguo TUE como aquellos actos de la PESC que se dirigen a situaciones específicas en las que se considere necesaria una acción operativa de la Unión, fijándose los objetivos, el alcance, los medios que deba facilitar a la Unión, las condiciones de su ejecución y, en caso necesario, su duración ${ }^{64}$. De este modo, la decisión de acción de la Unión designa la acción operativa de la misión con el fin de lograr los objetivos fijados por el Consejo, y que toman como punto de referencia las orientaciones generales fijadas por el Consejo Europeo.

Esta decisión de creación de una misión de paz de la UE tiene variantes significativas en función del tipo de misión, militar, civil o mixta. La aprobación de la creación de la misión abre, por consiguiente, un nuevo proceso, el de la constitución en sentido propio de la misión, que incluye, en su caso, la creación del Comité de contribuyentes cuando existe una participación exterior.

\subsection{El factor tiempo en la planificación y establecimiento de las misiones}

Las primeras misiones iniciadas por la UE en el 2003, la MPUE en Bosnia y CONCORDIA en la ARYM, pusieron de manifiesto una serie de problemas presentes en la fase de planificación de estas misiones, con especial relevancia de los financieros, que, inevitablemente, repercutieron en una mayor lentitud en esta fase de concepción y en su posterior despliegue.

\subsubsection{Problemas de financiación y más}

Estos problemas vinculados en general a la financiación pueden resumirse como siguen:

1. Por un lado, el recurso a distintos mecanismos de financiación comprometió una realización eficiente de estas misiones. Puesto que cada mecanismo de financiación estaba previsto para una misión concreta, no se logró

\footnotetext{
63 Art. 28.3 del TUE.

${ }^{64}$ Antiguo art. 14.1 del TUE.
} 
planear una economía de escala ni el aprovechamiento de las sinergias en la gestión y la eficacia. De este modo, se duplicaba la gestión, se dificultaba la dotación de personal y el establecimiento del régimen de responsabilidades. Era necesario, pues, establecer una estructura administrativa capaz de minimizar riesgos y costes.

2. Otro factor problemático fue el de las previsiones de los costes. Las previsiones financieras establecidas en las acciones comunes tendían a subestimar el coste real de la operación. Estas previsiones se basaron en la experiencia de la ONU y no tomaban como referencia las consecuencias del mandato, el tamaño y la organización totalmente distintas. De modo que el Consejo de la Unión instó a aumentar las primeras peticiones de contribuciones en un 30 por 100 del importe de referencia.

3. Finalmente, la coordinación con los Estados terceros a través de los mecanismos financieros creados implicaba demasiado tarde a estos Estados en el proceso de toma de decisiones. Ello complicaba la obtención a tiempo de la cobertura financiera necesaria de los costes de la misión ${ }^{65}$. La consecuencia derivada de esta falta de coordinación era la de que el Estado encargado de dirigir la operación acababa asumiendo la mayor parte de los costes de la operación. Esto le sucedió a Francia durante la operación CONCORDIA (2003), al tener que aportar 600.000 euros adicionales para cubrir los costes de los preparativos ${ }^{66}$. El tiempo que resultó necesario para poner en marcha una operación militar relativamente pequeña, puso de manifiesto la necesidad de iniciar con mayor antelación los preparativos de cualquier operación militar que la UE pueda acometer en el futuro y el establecimiento de un mecanismo duradero y estable de financiación ${ }^{67}$.

Asimismo, la primera misión en Bosnia y Herzegovina, la MPUE (2003), exigió nueve meses de planificación desde la adopción de la decisión de principio hasta el inicio efectivo de la misión. Previamente a su despliegue, en la fase de planeamiento durante el 2002, fueron llevadas a cabo tres breves misiones de recogida de datos en Sarajevo. Las recomendaciones de estas misiones constituyeron las bases para establecer el mandato, la estructura y el presupuesto de la misión, que no empezaría sobre el terreno hasta el 1 de enero de $2003^{68}$. Además, la misión se encontró con otros problemas en su fase de inicio, a pesar de haberse beneficiado de este largo periodo de planeamiento. Como ejemplo, cabe citar la falta del apoyo necesario por parte de las direcciones de la Secretaría General del Consejo, o la falta de

65 Lindstrom, G., «Operaciones PESD en la práctica», en Gnesotto, N. (ed.), Política de Seguridad y Defensa de la Unión Europea..., op. cit., nota 37, pp. 136-137.

66 Doc. 11154/1/03, «Operaciones militares-aspectos financieros. Enseñanzas de la primera operación militar de la UE (Concordia)», Bruselas, 15 de septiembre de 2003, p. 8. Incluso la OTAN tuvo que proporcionar equipo esencial que la UE no pudo proporcionar en la fase de preparación por la falta de fondos, así como avanzar determinados pagos a cargo de la operación.

67 Ibid., p. 3.

68 Doc. 11206/03, «Lessons from the planning of the EU Police Mission in Bosnia and Herzegovina (EUPM)», 14 de julio de 2003, pp. 3-4, donde se recogen las aportaciones de estos órganos con relación a la MPUE (2003). En http://register.consilium.europa.eu/pdf/en/03/st11/st11206.en03.pdf (fecha de consulta: 22 de abril de 2011). 
diligencia de los Estados miembros para facilitar la ejecución del mandato de la misión ${ }^{69}$.

La preparación del despliegue de la siguiente misión en Macedonia, CONCORDIA (2003) — por la que la UE asumía la sustitución de las fuerzas de la OTAN-, también se encontró con obstáculos en su fase de planificación, además de los financieros, puesto que esta nueva misión militar requería el establecimiento de un acuerdo previo y definitivo de colaboración entre la OTAN y la UE, que se retrasó en el tiempo. A pesar de que la UE había manifestado su voluntad de sustituir a la OTAN en junio de 2002, la determinación de los medios y capacidades, incluidas las opciones de mando a las que la UE podía recurrir para la realización de operaciones de gestión de crisis en las que no estuviera implicada la OTAN, constituyeron un obstáculo para alcanzar un acuerdo, ante el bloqueo sistemático de Turquía del proceso negociador. Una vez superado este obstáculo, y alcanzado un acuerdo global en diciembre de 2002 con la OTAN (a través de la firma de los acuerdos Berlín Plus), la UE pudo adoptar a principios de 2003 las decisiones relativas para tomar el relevo de la OTAN en la ARYM, lanzando finalmente la misión el 18 de marzo de $2003^{70}$.

\subsubsection{Creación del mecanismo ATHENA}

La detección de los problemas financieros comentados comportó la creación, en marzo de 2004, del mecanismo financiero ATHENA, que gestiona los costes comunes de las misiones militares de la UE con el fin de poner término a estas dificultades iniciales de financiación ${ }^{71}$. El objeto de este mecanismo es aumentar la flexibilidad y celeridad en la administración de los costes comunes, con independencia de la complejidad o urgencia de la misión. Así, se ha establecido un comité especial —formado por un representante de cada uno de los Estados miembros participantes, excepto Dinamarca- que es el encargado de aprobar todos los presupuestos de financiación de los costes comunes. Sus decisiones son vinculantes y deben tomarse por unanimidad $^{72}$. Aunque el nuevo art. 41.3 del TUE prevé la sustitución de este mecanismo por un fondo inicial —integrado por las aportaciones de los países con mayor RNB_-, que debería hacer frente a los gastos iniciales de cualquiera de los tipos de operaciones recogidos en el art. 43 del TUE, éste todavía no se ha creado. La última misión militar desplegada hasta el mo-

\footnotetext{
69 Merlingen, M., «The EU Police Mission in Bosnia and Herzegovina (EUPM)», en GnesotTo, N., (ed.), Política de Seguridad y Defensa de la Unión Europea..., op. cit., nota 37, p. 167.

${ }^{70}$ Gross, E., "EU military operation in the former Yugoslav Republic of Macedonia (Concordia)», en ibid., nota 37, pp. 175-176.

71 Véase la última modificación en la Decisión 2011/871/PESC del Consejo, de 19 de diciembre (DO L 343/35, de 23 de diciembre de 2011).

72 Véase Lindstrom, G., op. cit., nota 65, pp. 134-140, en las que realiza un análisis detallado de los tres tipos de dificultades, financieras, operativas y de planteamiento que han puesto en evidencia la realización de las misiones tanto civiles como militares de la UE.
} 
mento, EUTM Mali (2013), financia sus costes comunes de acuerdo con el mecanismo ATHENA ${ }^{73}$.

Estas dificultades iniciales de financiación, unidas a la urgencia de la situación y el personal y medios requeridos, así como el contexto político de la situación, no han sido obstáculo para que, de modo general, la UE haya demostrado su capacidad para responder en un modo y tiempo adecuados a las diversas crisis planteadas.

Así, la preparación de la MAFUE en Rafah (2005) necesitó aproximadamente unas tres semanas de preparación y su fase operativa empezó el 25 de noviembre de 2005, pocos días después de que los Estados miembros decidieran su lanzamiento ${ }^{74}$. Mientras que el lanzamiento de las misiones EUFOR RD Congo (2006) y ALTHEA en Bosnia (2004), se llevó a cabo en dos y ocho meses, respectivamente ${ }^{75}$. Otras misiones no plantearon problemas en la planificación previa, como es el caso de EUPOL Kinshasa (2005) y su prolongación EUPOL RD Congo (2007). La primera contó con el despliegue de parte de su personal en febrero de 2005 y sería lanzada oficialmente el 12 de abril de 2005. Posteriormente, EUPOL RD Congo (2007) daría continuidad a la primera sin que mediara ningún lapso de tiempo entre ambas ${ }^{76}$. Igualmente, la misión EUMM Georgia (2008), de considerables dimensiones y desarrollada en una zona en conflicto, fue desplegada en menos de un mes, lo que representó un logro importante para la Unión, al demostrar su capacidad para reaccionar rápidamente ante una situación de grave crisis, a pesar de que posteriormente el proceso de ejecución se encontraría con un número diverso de problemas logísticos, técnicos y políticos ${ }^{77}$.

Para la realización de la primera operación militar de la Unión, ARTEMIS en la RD Congo (2003), de tres meses de duración, tanto el AR como el COPS adoptaron en un espacio breve de tiempo, entre una y dos semanas, el conjunto de decisiones que requerían la puesta a punto de una misión de estas características, marcada por el hecho de que era la primera fuera del continente europeo; la de mayor envergadura hasta ese momento; la más compleja en cuanto a sus funciones; y además, fue realizada de modo autónomo, sin recurrir a las capacidades y medios de la OTAN. Esta operación consiguió, pues, sus objetivos, entre los que cabe señalar un rápido despliegue en una zona remota, además de la capacidad de proteger a la población civil con un

\footnotetext{
73 Art. 10.1 de la Decisión 2013/34/PESC, op. cit., nota 17.

74 Bulut, E., «The EU Border Assistance Mission at the Rafah Border Crossing Point (EUBM Rafah)», en Grevi, G., Helly, D. y Keohane, D. (eds.), European Security and Defence policy. The first 10 years (1999-2009), París, EU ISS, 2009, p. 302.

75 RuYs, T., «Background Paper on EU Crisis Management Operations», Institute for International Law, Working paper, 2007, núm. 108, p. 27. En http://www.law.kuleuven.be/iir/nl/wp/WP/WP108e.pdf (fecha de consulta: 22 de marzo de 2009).

${ }^{76}$ VIRCoulon, Th., «The EU police mission in Kinshasa-DRC (EUPOL Kinshasa) and the EU Police mission in RD Congo (EUPOL RD Congo)», en GRevi, G., Helly, D. y Keohane, D. (eds.), European Security and Defence Policy..., op. cit., nota 74, pp. 223 y 225.

77 Fischer, S., «The European Union Monitoring Mission in Georgia (EUMM)», en ibid., nota 74, pp. 386-390.
} 
mínimo de bajas y la coordinación con otras organizaciones internacionales presentes en la zona ${ }^{78}$.

Así, vemos que el factor tiempo en la fase de planificación de la misión viene condicionado por múltiples variables: financieras, políticas, técnicas, institucionales, etcétera.

\section{DESPLIEGUE}

\subsection{Concreción de la misión y lanzamiento}

La misión autorizada debe ser definida con claridad antes de su constitución y lanzamiento. En esta fase se deben elaborar, tal y como se prevé en la decisión de creación de la misión, el concepto de las operaciones (CONOPS), el Acuerdo sobre el estatuto de las fuerzas (SOFA) o el Acuerdo sobre el estatuto de la misión (SOMA), así como el plan de misión (OPLAN). Posteriormente, y en caso de que participen terceros Estados, el COPS deberá crear también un Comité de contribuyentes (CDC), con el fin de integrar a estos Estados en la gestión diaria de la misión, y deberán asimismo celebrarse los distintos acuerdos de participación de estos Estados.

\subsubsection{El concepto de las operaciones}

Siguiendo la previa recomendación del COPS, el comandante de la operación y la Unidad de policía desarrollarán el concepto de las operaciones (CONOPS) para las misiones militares y civiles. Para las operaciones militares, el COPS requiere al CMUE para que desarrolle este concepto, mientras que para las operaciones civiles el COPS, siguiendo el requerimiento del AR, requiere a la Unidad de policía para que lo elabore.

En el caso de que sea necesario el uso de otros instrumentos civiles, se seguirá un procedimiento de planificación similar al que hemos visto, con la adopción de documentos de planificación específicos.

Una vez recibida la recomendación del CMUE y del CIVCOM, el COPS envía el CONOPS militar y/o de policía, al mismo tiempo que los documentos de planificación para otros instrumentos civiles, al Consejo para su aprobación. Una vez aprobado, el COPS inicia el proceso de generación de la fuerza que es liderado por el comandante de la operación en coordinación con el EMUE para las capacidades militares ${ }^{79}$ y por el jefe de policía (con el apoyo de la Unidad de policía) para las capacidades de policía. La generación del resto de aspectos civiles se realiza a través del Mecanismo de coordinación ${ }^{80}$.

\footnotetext{
78 Helly, D., «The EU military operation in DR Congo (Artemis)», en ibid., nota 74, pp. 183-184.

79 Para las operaciones militares este proceso puede implicar también la organización de conferencias de generación de fuerzas o reuniones del COPS con el Consejo de la OTAN.

80 Doc. 11127/03, "Phase 4 Formal decision to take action, development of planning documents», op. cit., nota 25 , pp. $17-20$.
} 
Siguiendo con la misión EUPOL Afganistán (2007), el CAE de abril de 2007 aprobó el Concepto de operaciones (CONOPS) para la misión y al mes siguiente el Consejo aprobaba la Acción común 2007/369/PESC por la que se establecía la base jurídica de la misión ${ }^{81}$. De este modo, el CONOPS es aprobado por el Consejo, por norma general, antes de la creación de la misión, como nos muestran los ejemplos de esta misión y también las misiones en los Balcanes occidentales ${ }^{82}$. Al mismo tiempo, el Consejo también invitará a la Comisión para que presente propuestas adecuadas o adopte medidas (en el ámbito de sus competencias) con la finalidad de cumplir los objetivos políticos seleccionados en este concepto. Además, invitará a los Estados miembros para que orienten su acción de acuerdo con el concepto aprobado.

\subsubsection{Elaboración y adopción de los acuerdos sobre el estatuto del personalffuerza}

Cuando lo considerase adecuado, la Secretaría del Consejo era la encargada de preparar el borrador del Acuerdo sobre el estatuto de las fuerzas/personal (SOFA) de la misión, que era pasado al Consejo por el COPS sobre la base de los consejos sobre las cuestiones militares aportados por el CMUE. Estos consejos eran aportados por el CMUE después de la consulta previa con el comandante de la operación. En el caso de las misiones no militares, se seguía el mismo proceso. En este caso, el COPS aportaba las recomendaciones del CIVCOM sobre los aspectos civiles, y éste previamente había consultado al jefe de policía o de misión. A partir de aquí, se iniciaba el proceso de celebración del acuerdo internacional, en aplicación del art. 37 del TUE (antiguo art. 24).

\subsubsection{Elaboración y adopción del plan de operaciones}

El borrador o proyecto del plan de operaciones (OPLAN) — que puede incluir las normas de intervención, en caso necesario-, es preparado por el Grupo de planeamiento dirigido por el comandante de la operación para las operaciones militares, y por el jefe de policía, asistido en caso necesario por la unidad de policía, para las operaciones de policía. En el caso de otros instrumentos civiles, se sigue también un procedimiento similar. Así, para la misión EUPOL Kinshasa (2005), la Acción común 2004/847/PESC establecía, en relación con la fase de planeamiento de la operación, que:

«[...] el Grupo de Planeamiento elaborará el plan de operación (OPLAN) y desarrollará todos los instrumentos técnicos necesarios para ejecutar la EUPOL $\mathrm{KISNHASA} »{ }^{83}$.

\footnotetext{
81 Véase la Acción común 2007/369/PESC, op. cit., nota 41.

${ }^{82}$ Véase, como ejemplo, el art. 2.4 de la Acción común 2003/681/PESC, op. cit., nota 40, para la misión EUPOL PRÓXIMA (2003).

83 Art. 2.3 de la Acción común 2004/847/PESC del Consejo, de 9 de diciembre (DO L 367/30, de 14 de diciembre de 2004).
} 
Con posterioridad, el COPS valora el proyecto, siguiendo la opinión del CMUE y del CIVCOM del OPLAN y lo transmite al Consejo. Éste se encargará finalmente de aprobar el OPLAN (o documentos equivalentes), incluidas las normas de intervención. La aprobación por parte del Consejo entendemos que no requiere la unanimidad, puesto que se trata de una decisión interna de desarrollo de la decisión principal de creación de la misión.

En todo caso, las decisiones de creación de las misiones estudiadas se limitan a establecer que: «El Consejo aprobará el CONOPS y el OPLAN». Por otro lado, cuando la misión ya esté en ejecución, el COPS estará autorizado por el Consejo a modificar el OPLAN y también el CONOPS ${ }^{84}$.

\subsubsection{Creación del Comité de contribuyentes y acuerdos de participación}

La decisión de creación de la misión también puede establecer la autorización del Consejo al COPS para que prepare el establecimiento de un Comité de contribuyentes (CDC), que será establecido por una decisión suya. En este sentido, el COPS examinará, de acuerdo con las necesidades específicas de la operación, si debe establecerse un CDC conjunto para la operación militar y para otros elementos (de policía o de otro tipo civil). También podría establecerse un CDC para operaciones civiles, a menos que el COPS decida lo contrario. Sin embargo, esta previsión sólo está contenida en aquellas acciones que permiten la participación de terceros Estados en la operación. En concreto el COPS decide:

a) La creación del Comité de contribuyentes. Así por ejemplo, el COPS aprobó las decisiones de creación de este comité para la misiones: MPUE (2003) ${ }^{85}$; EUFOR ALTHEA (2004) ${ }^{86}$; CONCORDIA (2003) ${ }^{87}$; EUPOL PRÓXIMA (2003) ${ }^{88}$; ARTEMIS $(2004)^{89}$, con el fin de permitir la gestión diaria de estas misiones entre los terceros Estados participantes y los miembros de la UE para estas misiones realizadas en Bosnia-Herzegovina, Macedonia y la RD Congo.

b) La aceptación de contribuciones de terceros Estados, así como sus modificaciones. Como ejemplos, el COPS aceptó estas contribuciones para las misiones CONCORDIA (2003) ${ }^{90}$; PRÓXIMA (2003) ${ }^{91}$; EUFOR ALTHEA

84 Véase, por ejemplo, el art. 2 de la Acción común 2004/847/PESC, op. cit., nota 83, para la misión EUPOL Kinshasa (2005) y su continuación EUPOL RD Congo (2007).

85 Decisión MPUE/1/2005 del COPS, de 4 de marzo (DO L 72/23, de 18 de marzo de 2005).

86 Decisión 2004/739/PESC, BiH/3/2004 del COPS (DO L 325/64, de 28 de octubre de 2004).

87 Decisión 2003/C 62/1, FYRM/1/2003 del COPS, de 18 de febrero (DO L C 62/1, de 15 de marzo de 2003).

88 Decisión 2005/230/CE, PROXIMA/3/2005 del COPS, de 4 de marzo ( $D O$ L 72/25, 18 de marzo de 2005).

${ }_{89}$ Decisión 2003/529/PESC, RDC/2/2003 del COPS, de 11 de julio (DO L 184/13, de 23 de julio de 2003).

90 Decisión 2003/497/PESC, ERYM/2/2003 del COPS, de 10 de marzo (DO L 170/15, de 9 de julio de 2003).

91 Decisión 2004/190/PESC, PRÓXIMA/1/2004 del COPS, de 10 de febrero (DO L 60/54, de 27 de febrero de 2004). 
$(2004)^{92}$, y ARTEMIS (2003) ${ }^{93}$. Todas estas decisiones aceptan la participación de terceros Estados en las misiones de paz de la UE, antes de la creación del CDC, y una vez obtenida la recomendación del comandante al CMUE y de éste al COPS.

Estas decisiones son adoptadas por delegación del Consejo al COPS como decisiones de desarrollo de la acción principal (en la que se prevé la posibilidad de crear este Comité o aceptar las contribuciones de terceros Estados participantes en la misión) y por ello entendemos que son aprobadas por mayoría cualificada (art. 31.2 del TUE).

Por otro lado, llegados a esta fase, la UE también debe negociar con los terceros Estados participantes los acuerdos internacionales que regirán su estatuto, así como las aportaciones, tanto en recursos humanos como financieros a la misión, en aplicación del art. 37 del TUE, excepto en el caso de que ya exista un Acuerdo marco previo ${ }^{94}$.

\subsubsection{Nombramiento del jefe de misión}

Correspondería también al Consejo aprobar todas las decisiones relativas al nombramiento del jefe de misión/jefe de policía/jefe de la fuerza militar, tal y como sucedió, por ejemplo, con la adopción de la Decisión 2002/212/PESC para el nombramiento del jefe de misión de la MPUE (2003) en Bosnia ${ }^{95}$.

En pocos casos, como el de las misiones EUFOR RD Congo (2006), EUTM Somalia (2010) y EUTM Mali (2013), este nombramiento está presente en la decisión de creación de la misión ${ }^{96}$. Sin embargo, de la práctica de las misiones de la UE se desprende que el Consejo ha autorizado al COPS, bajo su autoridad, y a través de las acciones de creación de las misiones, a adoptar las decisiones sobre cuestiones relativas a:

a) El nombramiento y las prórrogas de los jefes de misión/de policía o de los jefes de la fuerza militar de la UE. Así, el COPS aprobó los nombramientos de jefes de misión/de policía para las misiones: PRÓXIMA (2003) ${ }^{97}$; EUPAT en Kosovo (2005) ${ }^{98}$; EUSSR Guinea-Bissau (2008) ${ }^{99}$; y más reciente-

92 Decisión 2004/732/PESC, BiH/1/2004 del COPS, de 21 de septiembre (DO L 324/20, de 27 de octubre de 2004).

93 Decisión 2003/500/PESC, RDC/1/2003 del COPS, de 1 de julio ( $D O$ L 170/19, de 9 de julio de 2003).

94 Como, por ejemplo, el Acuerdo entre la Unión Europea y Canadá por el que se crea un marco para la participación de Canadá en las operaciones de la Unión Europea de gestión de crisis ( $D O$ L 315/21, de 1 de diciembre de 2005).

95 Decisión 2002/212/PESC del Consejo, de 11 de marzo ( $D O$ L 70/8, de 13 de marzo de 2002).

96 Art. 2 de la Acción común 2006/319/PESC del Consejo, de 27 de abril (DO L 116/98, de 29 de abril de 2006); art. 2 de la Decisión 2010/96/PESC (EUTM Somalia), op. cit., nota 13, y art. 2 de la Decisión 2013/34/PESC (EUTM Mali), op. cit., nota 17.

97 Decisión 2004/846/CE, Próxima/2/2004 del COPS, de 30 de noviembre (DO L 367/29, de 14 de diciembre de 2004).

98 Decisión 2005/957/PESC, EUPAT/1/2005 del COPS, de 7 de diciembre (DO L 346/46, de 29 de diciembre de 2005).

99 Decisión UE SSR GUINEA-BISSAU/1/2008 del COPS, de 5 de marzo (DO L 73/34, de 15 de marzo de 2008). 
mente, EUCAP NESTOR (2012) ${ }^{100}$; EUCAP SAHEL Níger (2012) ${ }^{101}$, y EUAVSEC Sudán del sur (2012) ${ }^{102}$.

b) También adoptó, por ejemplo, la decisión sobre el nombramiento, previa recomendación del comandante de la operación, del jefe del elemento de mando UE de Nápoles para la operación militar EUFOR ALTHEA (2004) ${ }^{103}$.

Al tratarse todas ellas de decisiones de ejecución de la decisión principal, autorizadas previamente por el Consejo y relacionadas con el control político y la dirección estratégica de la operación, éstas son aprobadas por mayoría cualificada (art. 31.2 del TUE).

\subsubsection{Decisión de lanzamiento de la misión}

La finalización de esta fase se produce con la decisión de lanzamiento de la operación tomada por el Consejo. A través de ella el Consejo aprueba el OPLAN; decide el lanzamiento de la operación, cumplidas todas las condiciones previas para la generación de la fuerza o la valoración de los aspectos civiles y aprueba, en caso necesario, el Acuerdo sobre el estatuto de las fuerzas ${ }^{104}$.

Así, siguiendo con el ejemplo de la misión EUTM Somalia, el 15 de febrero de 2010, el Consejo aprobó la Decisión 2010/96/PESC de creación de esta misión, en la que establecía también el nombramiento del comandante de la operación y de la fuerza ${ }^{105}$; y el 31 de marzo siguiente, el Consejo aprobó, por medio de la Decisión 2010/197/PESC, el plan de operación (OPLAN) y el inicio de la misión, fijado para el 7 de abril. Al mismo tiempo, y como especificidad propia de las misiones militares, en la misma decisión el Consejo autorizaba, con efectos inmediatos, al comandante de la misión a dictar la orden de activación (ACTORD), a fin de desplegar las fuerzas y dar inicio a la ejecución de la misión ${ }^{106}$.

Así pues, el Consejo, en aplicación del art. 31.2 del TUE, ha adoptado por mayoría cualificada las decisiones sobre el inicio de las operaciones milita-

100 Decisión EUCAP NESTOR/1/2012 del COPS, de 17 de julio (DO L 198/16, de 25 de julio de 2012).

101 Decisión EUCAP SAHEL Níger/1/2012 del COPS, de 17 de julio (DO L 200/17, de 27 de julio de 2012).

102 Decisión EUAVSEC Sudán del sur 1/2012 del COPS, de 10 de agosto ( $D O$ L 229/25, de 24 de agosto de 2012).

103 Decisión 2007/725/PESC, BiH/12/2007 del COPS, de 25 de septiembre (DO L 293/9, de 10 de noviembre de 2007).

104 En esta fase también serán aprobadas y puestas en marcha las medidas de política exterior adoptadas por la Comisión Europea. Al mismo tiempo, la UE continuará manteniendo contactos, consultas, cooperación y diálogo con la OTAN, con miembros de la OTAN que no son miembros de la UE, con otros países candidatos a la adhesión, con socios potenciales como Canadá, Rusia y Ucrania y con la ONU y otras organizaciones internacionales y regionales (OSCE, Consejo de Europa, etc.), así como ONG, etcétera.

105 Art. 2 de la decisión 2010/96/PESC, op. cit., nota 13.

106 Arts. 1, 2 y 3 de la Decisión 2010/197/PESC del Consejo, de 31 de marzo (DO L 87/33, de 7 de abril de 2010). 
res CONCORDIA (2003) ${ }^{107}$; ARTEMIS (2003) ${ }^{108}$; EUFOR ALTHEA (2004) ${ }^{109}$; EUFOR Chad/RCA (2008) ${ }^{110}$; ATALANTA (2008) ${ }^{111}$; EUTM Somalia (2010) ${ }^{112}$, y EUTM Mali (2013) ${ }^{113}$.

En cambio, para las misiones no militares, no consta ninguna decisión que establezca el inicio de la misión. Por norma general, éste está previsto en la propia decisión (o antigua acción común) de creación de la misión. Así, por ejemplo, para la misión EULEX Kosovo (2008), se vinculaba la decisión de poner en marcha la misión a la aprobación del OPLAN por parte del Consejo. Asimismo, por las circunstancias especiales que han rodeado a esta misión, se establecía un periodo transitorio para el inicio de la fase operativa de la misión, que se iniciaría «al transferirse la autoridad de la Misión de las Naciones Unidas en Kosovo, UNMIK»114.

En otros casos, la decisión es más concreta y establece las fechas aproximadas de planeamiento y ejecución. Para la misión EUPOL Afganistán (2007), el Consejo precisaba que la fase de planeamiento se iniciaría el 30 de mayo de 2007 y la fase operativa comenzaría «a más tardar, el 15 de junio de 2007» "115. O la misión de observación MOA en Indonesia (2005), cuya fase operativa se inició el 15 de septiembre de $2005^{116}$. Aunque otras acciones comunes no son tan precisas y establecen fechas aproximadas para el inicio de la misión, como en el caso de EUMM Georgia (2008), que preveía un despliegue en dos fases. El principio del despliegue en septiembre de 2008 y el comienzo de la fase operativa no más tarde del 1 de octubre de $2008^{117}$. En otros casos, la acción sólo menciona las fechas de entrada en vigor y de expiración de la acción y la fecha de inicio de la fase operativa es anunciada en notas de prensa, como, por ejemplo, en las misiones EUPOL Kinshasa (2005) y EUSEC RD Congo (2005) ${ }^{118}$.

107 Decisión 2003/202/PESC del Consejo, de 18 de marzo (DO L 76/43, de 22 de marzo de 2003).

108 Decisión 2003/432/PESC del Consejo, de 12 de junio (DO L 147/42, de 14 de junio de 2003).

109 Decisión 2004/803/PESC del Consejo, de 25 de noviembre (DO L 353/21, de 27 de noviembre de 2004).

110 Decisión 2008/101/PESC del Consejo, de 28 de enero (DO L 34/39, de 8 de febrero de 2008).

111 Decisión 2008/918/PESC del Consejo, de 8 de diciembre (DO L 330/19, de 9 de diciembre de 2008).

112 Decisión 2010/197/PESC, op. cit., nota 106.

113 Decisión 2013/87/PESC del Consejo, de 18 de febrero (DO L 46/27, de 19 de febrero de 2013).

114 Art. 5.1 de la Acción común 2008/124/PESC, op. cit., nota 11.

115 Art. 1.1 de la Acción común 2007/369/PESC, op. cit., nota 41.

116 Art. 1.1 de la Acción común 2005/643/PESC del Consejo, de 9 de septiembre (DO L 234/13, de 10 de septiembre de 2005).

117 Art. 1.1 de la Acción común 2008/736/PESC del Consejo, de 15 de septiembre (DO L 248/26, de 17 de septiembre de 2008).

118 Véase EU Council Secrétariat, Background, «L'engagement de l’Union européenne pour la stabilité et la sécurité en République démocratique du Congo (RDC)», RDC/00 (initial) 23 de mayo de 2005, en http://www.consilium.europa.eu/uedocs/cmsUpload/Background-23.5.05.fr.pdf (fecha de consulta: 13 de marzo de 2009). 


\subsection{El factor tiempo en el lanzamiento y despliegue de las misiones}

El proceso de despliegue de la misión sobre el terreno en un tiempo prudencial también es esencial para garantizar un correcto desarrollo de la misma. Muchas veces el tiempo para el despliegue es diferido a causa de retrasos ya en la fase previa de planificación, como hemos visto supra.

\subsubsection{La planificación como condicionante del despliegue}

En la misión de observación de la UE en Aceh, MOA (2005), el tiempo previsto para iniciar el despliegue fue muy dilatado a causa de la falta de unidad entre los Estados miembros y las instituciones en el proceso de toma de decisiones durante la fase de planificación. Por un lado, Finlandia, Suecia, los Países Bajos, Francia y el Reino Unido estaban a favor de esta actuación, mientras que otros países preferían concentrar las misiones en zonas más cercanas a Europa. Además, el proceso de financiación acentuó las divisiones, lo que impidió el despliegue de la misión inicialmente previsto para el 15 de agosto de 2005. Finalmente, la intervención del AR de la PESC, y la asunción de parte de los costes iniciales por parte del Reino Unido, permitirían lanzar la operación el 15 de septiembre, un mes más tarde de lo previsto ${ }^{119}$.

La operación EUFOR RD Congo (2006), desarrollada durante la primera mitad de 2006, tuvo un lapsus de tiempo de desarrollo y preparación de unos seis meses, que se inició con la solicitud del CSNU el 27 de diciembre de 2005, hasta la decisión tomada por el Consejo de la UE de lanzar la operación el 12 de junio de 2006. Sin embargo, la preparación de la misión propiamente dicha no se iniciaría por parte de las estructuras de la PCSD hasta enero de 2006. Además, en la primera fase de consultas, se encontraron con problemas que afectarían a su ejecución. A pesar de que los Estados miembros estaban en general a favor de desplegar una operación en la RD Congo, no se anunciaron para ello suficientes contribuciones y ninguno de los mayores Estados quería liderar la operación. Sólo después de la consecución de un acuerdo político el 14 de marzo entre Alemania y Francia - fuera del marco de la UE, y por el cual Francia desplegaría un contingente equivalente al de Alemania, mientras que ésta lideraría la operación-, se pudo continuar con el proceso para su ejecución y despliegue sobre el terreno. Así, una semana después, el COPS acordó el concepto de gestión de crisis y desde finales de marzo en adelante el cuartel general ubicado en Potsdam inició la planificación militar y envió la primera de varias misiones de recogida de datos a Kinshasa. Finalmente, el 27 de abril, el CAGRE adoptaría la acción común, en aplicación del mandato del CS para desplegar, dos días después, la operación en el teatro de operaciones ${ }^{120}$.

119 Schulze, K. E., «The Aceh Monitoring Mission», en Grevi, G., Helly, D. y Keohane, D. (eds.), European Security and Defence Policy..., op. cit., nota 74, p. 268.

120 Von Ordanza, N., «EU Military Deployment - An Executive Prerogative? Decision - making and parliamentary control on the use of force by the EU», Paper, 23 de abril de 2008, p. 19, en http://www. 
Otro factor a tener en cuenta para el despliegue de tropas militares, y puesto en evidencia en esta operación por Nicolai Von Ordanza, es la aprobación que deben otorgar los parlamentos nacionales. En el caso de Alemania, la aprobación del Bundestag, requerida antes del inicio de las operaciones, no llegaría hasta el 1 de junio de 2006, más de un mes después del acuerdo político al que habían llegado Francia y Alemania, y dos meses más tarde del inicio de las tareas de planificación del cuartel general en Potsdam ${ }^{121}$.

En cambio, la primera misión naval militar, ATALANTA (2008), fue planificada y ejecutada, en cuanto al factor tiempo, sin mayores problemas. Una vez aprobada la acción, el 10 de noviembre de 2008, la capacidad operativa inicial fue alcanzada el 13 de diciembre de 2008. Además, los doce primeros meses de la operación fueron divididos en tres fases de cuatro meses cada una (diciembre-marzo, abril-julio, agosto-noviembre), permitiendo la incorporación progresiva de los Estados miembros participantes. Tal y como se había planeado, la fase 1 fue ejecutada por el Reino Unido, Francia y Grecia, que tenía el mando de la fuerza. La fase 2 comportó la participación adicional de España, Alemania e Italia, y la fase 3 la de los Países Bajos y Bélgica que se unieron a la operación ${ }^{122}$.

\subsubsection{Obstáculos internos y externos}

Por otro lado, algunas operaciones han mostrado su lentitud a partir del momento en que son desplegadas sobre el terreno debido a dificultades y obstáculos internos o externos, que han ido apareciendo durante el despliegue de la misión. Así, muchas de ellas se han encontrado con algún tipo de problema, político, logístico, de seguridad, etc., si no todos a la vez, que han condicionado de un modo u otro el tiempo empleado en la planificación previa al lanzamiento de la operación, o bien su ejecución posterior sobre el terreno.

En el caso de las operaciones PRÓXIMA (2003) y su continuación EUPAT (2005) en la ARYM, tres meses después del despliegue de PRÓXIMA, algunos de los oficiales de campo todavía no habían recibido ordenadores ni otros equipos de oficina esenciales para llevar a cabo su trabajo. Para que la misión pudiera iniciar su trabajo a tiempo, fue esencial la ayuda recibida por parte de la OSCE. Ello muestra la necesidad de asegurarse durante la fase de

ies.be/files/repo/conference2008/EUinIA_IX_2_vonOndarza.pdf (fecha de consulta: 5 julio 2011). Véase también MAJOR, C., «The military operation EUFOR RD Congo 2006», en op. cit., GNESOTTO, N. (ed.), Política de Seguridad y Defensa de la Unión europea..., op. cit., nota 37, p. 315.

121 Von ORDanza, N., op. cit., nota 120, pp. 20-21. En todo caso, Ordanza señala que, a pesar de que un rechazo a la participación alemana en la operación EUFOR RD Congo hubiera sido posible, ello habría dañado seriamente la credibilidad del país ante la UE, las Naciones Unidas y su principal aliado en la operación, Francia.

122 Helly, D., «The EU military operation Atalanta», en Grevi, G., Helly, D. y Keohane, D. (eds.), European Security and Defence Policy..., op. cit., nota 74, pp. 396-397. 
planeamiento de que los equipos y material esencial se han enviado sobre el terreno, con el fin de poder iniciar la operación en la fecha prevista ${ }^{123}$.

Un problema similar se encontró la misión EUJUST THEMIS (2004) durante la fase de su despliegue en Georgia, puesto que durante los tres primeros meses, debido también a la complejidad de los procedimientos de financiación de las operaciones no militares, la misión no contaba con ordenadores para realizar sus funciones. En este caso, el excesivamente ambicioso mandato de la misión comportó también que el tiempo previsto de la misma, un año, no fuera suficiente para alcanzar los objetivos también previstos en un entorno posrevolucionario ${ }^{124}$.

EUFOR ALTHEA (2004), que es citada como ejemplo entre los oficiales militares de la UE de un trabajo bien hecho, tuvo que hacer frente a desacuerdos políticos que alargaron seis meses el proceso de planificación política estratégica ${ }^{125}$. La utilización de las estructuras de la OTAN, en concreto del Cuartel General de la Operación de la UE, que está situado en el Cuartel General Supremo de las Fuerzas Aliadas en Europa (SHAPE), comportó la demanda de más información de parte de Turquía ${ }^{126}$.

En el caso de EUPOL COPSS en los territorios palestinos (2006), la situación política influyó también en el despliegue de la misma sobre el terreno. La fase operativa de la misión se inició el 1 de enero de 2006 (apenas dos meses después de ser aprobada la misión por el Consejo, una vez recibida la invitación de la AP). Sin embargo, la victoria de Hamas en las elecciones legislativas celebradas en el mismo mes comportó una actuación vacilante y entrecortada de la misión en sus inicios, puesto que el grupo de Hamas pasó a controlar el Ministerio del Interior ${ }^{127}$.

Asimismo, la operación militar EUFOR Chad/RCA (2008), lanzada en el 2007 con la aprobación en octubre de la acción común correspondiente, tuvo un despliegue inicial (para una operación de un año de duración) que no se desarrolló tal y como se había planeado. El concepto de operaciones (CONOPS) adoptado el 12 de noviembre de 2007 por el Consejo, fue seguido de cinco conferencias de generación de fuerzas, durante las cuales se demostraron las dificultades para obtener el suficiente número de tropas. A pesar de la

123 IoAnnides, I., «The EU Police Mission (EUPOL Proxima) and the European Union Advisory Team (EUPAT) in the former Yugoslav Republic of Macedonia», en ibid., nota 74, p. 194.

124 KurowsKa, X., "The rule-of-law mission in Georgia (EUJUST Themis)», en ibid., nota 74, pp. 205-207.

125 SIMON, L., "Crisis Management Just Won't Cut It Anymore: Military Planning and CSDP After Lisbon», p. 8, en Simon, L. y MATTELAER, A., EUnity of Command-The Planning and conduct of CSDP Operations, Royal Institute for International Relations, Academia Press, enero 2001, en $h t t p: / / w w w$. egmontinstitute.be/paperegm/ep41.pdf (fecha de consulta: 11 de junio de 2013).

126 SIMON, L., "Command and control? Planning for EU military operations», EU ISS, Occasional paper, enero 2010, núm. 81 , p. 29, en http://www.iss.europa.eu/uploads/media/Planning_for_EU_military_operations.pdf (fecha de consulta: 11 de junio de 2013).

127 Bulut, E., «The EU Police Mission for the Palestinian Territories -EU Coordinating Office for Palestinian Police Support (EUPOL COPPS)», en Grevi, G., Helly, D. y Keohane, D. (eds.), European Security and Defence Policy..., op. cit., nota 74, p. 291. 
urgente necesidad de estabilizar las fronteras del Chad con Sudán y proteger a los refugiados de Darfur, los Estados miembros tardaron cuatro meses para decidir quién aportaría las tropas, helicópteros y equipo médico, y quién pagaría la factura ${ }^{128}$. Finalmente, en la quinta conferencia, Francia, a pesar de su preferencia a limitar su contribución, acordó aumentarla aportando la mitad de las tropas, transporte aéreo y medios logísticos ${ }^{129}$. Además, una vez sobre el terreno, el despliegue de la operación peligró a causa de un ataque rebelde contra N’Djamena el 3 de febrero 2008, con lo que ésta no alcanzaría su capacidad operacional hasta el 15 de marzo de 2008, una vez restablecida la seguridad ${ }^{130}$.

En la misión EUPOL Afganistán (2007), también lanzada en el 2007, el problema también radicó en un lento despliegue sobre el terreno, sobre todo con relación a la aportación de los medios personales. Las dificultades logísticas en una zona complicada hicieron que, de las 230 personas previstas inicialmente, principalmente policías y expertos en justicia y aplicación del Derecho, sólo alrededor de 170 habían asumido sus puestos hacia mediados de 2008, más de un año después del lanzamiento de la misión ${ }^{131}$. Los retrasos en la planificación y el despliegue también se debieron a las dificultades en el reclutamiento de personal, afectando a la capacidad de la misión de estar presente fuera de Kabul. Esta dificultad fue debida a las reticencias de los Estados miembros a contribuir con el personal necesario. Sin embargo, por encima de estas dificultades, la misión debió hacer frente a retos políticos más amplios, relacionados con el estado del sector de la seguridad afgano y, por encima de todo, con la ardua coordinación de los esfuerzos para la reforma de la policía ${ }^{132}$.

El despliegue de la misión EULEX Kosovo (aprobada por el Consejo el 4 de febrero de 2008), estuvo condicionado por la Declaración Unilateral de Independencia de febrero de 2008, que afectaría también a su planificación y desarrollo posterior. Ante el dilema de desplegar la misión sólo en determinadas partes de Kosovo, la misión entró en un periodo operacional de hibernación hasta diciembre de 2008, cuando fue declarada su capacidad operacional inicial. La Resolución 1244 (1999) se mantuvo como marco legal de referencia, permitiendo así su despliegue sobre el terreno, operando bajo la autoridad y en el marco neutral del estatus de las Naciones Unidas. De este

128 Blockmans, S. y Wessel, R. A., op. cit., nota 62, pp. 283-284. Como señalan los autores, en un giro irónico del destino, los Estados miembros (que tan duramente habían criticado la incursión rusa en Georgia durante la Guerra de los cinco días en agosto de 2008), acabarían aceptando la oferta de Moscú para proveerles con cuatro Mi-8 MT helicópteros y hasta 120 miembros de personal, producto del acuerdo de participación firmado entre la UE y Rusia para esta operación.

129 Helly, D., "The EU military operation in the Republic of Chad and in the Central African Republic (Operation EUFOR Tchad/RCA)», en Grevi, G., Helly, D. y Keohane, D. (eds.), European Security and Defence Policy..., op. cit., nota 74, p. 341.

130 Ibid., p. 343.

131 Ibid., pp. 274-275.

132 Peral, L., "The EU Police Mission in Afghanistan (EUPOL Afghanistan)», en ibid., nota 74, pp. 331-332. 
modo, la fase operacional se iniciaría el 9 de diciembre de 2008, alcanzando su plena capacidad el 6 de abril de $2009^{133}$.

En el caso de la misión sobre la reforma del sector de la seguridad, EUSSR Guinea-Bissau (2008), la inestabilidad política en el país dificultó, durante varios meses, la planificación inicial sobre el terreno. Todo ello con el añadido de la dificultad para la misión de encontrar interlocutores apropiados entre las fuerzas armadas del país. A pesar de ello, la situación de violencia política que se vivía en aquellos momentos en el país no degeneró en una inseguridad general y la misión pudo continuar operando ${ }^{134}$.

En cambio, un ejemplo más reciente, el lanzamiento de la misión EUTM Mali (2013) se produjo el 18 de febrero de 2013, justo un mes después de aparecer publicada en el DOUE la decisión de creación de la misión, aprobada por el Consejo el 17 de enero ${ }^{135}$. En este caso, justo después de la intervención de Francia en el país, y ante la necesidad y el compromiso de la UE de dar una respuesta urgente a la crisis política, humanitaria y de seguridad que afecta a toda la región de Sahel ${ }^{136}$, se inició el despliegue paulatino de esta misión europea de formación militar y asesoramiento de las fuerzas de Mali.

\section{CONCLUSIONES}

Las misiones de paz europeas constituyen hoy día el instrumento principal de gestión de crisis de la UE. La declaración de operatividad de la PESD (2003) fue el punto de inflexión para el desarrollo de un sistema institucional y procedimental caracterizado simultáneamente por una gran complejidad y flexibilidad.

La complejidad se manifiesta, por un lado, en la intervención tanto de órganos propios del sistema institucional de la UE, como específicos, y de distinta naturaleza jurídico-política (Consejo, Comisión, AR, EMUE, COPS, etc.). También se manifiesta en el procedimiento no reglado de actuación regulado en el TUE —en relación con la adopción de decisiones de creación de las misiones por unanimidad, matizada por la abstención constructiva-; y en el documento interno del Consejo (2003) — con las sugerencias de actuación en

133 Grevi, G., «The EU rule-of-law mission in Kosovo (EULEX Kosovo)», en ibid., nota 74, pp. 359 y 362 .

134 Helly, D., "The EU mission in support of Security Sector Reform in Guinea-Bissau (EU SS Guinea-Bissau)», en ibid., nota 74, pp. 375.

135 Véase la Decisión 2013/34/PESC, op. cit., nota 17; y la Decisión 2013/87/PESC, op. cit., nota 113.

136 El interés de la UE en reducir la inseguridad y mejorar el desarrollo en la región del Sahel, llevó al Consejo a aprobar en marzo de 2011, como medida a largo plazo, una Estrategia para la seguridad y el desarrollo en el Sahel, a través de la cual pretende llevar a cabo un acercamiento global a la crisis de esta región en su conjunto, tanto alimentaria como el azote de los movimientos terroristas de carácter islámico. Véase FACTSHEet, «The European Union and the Sahel», Bruselas, 16 de enero de 2013, pp. 3 y 4, en http://www.europarl.europa.eu/meetdocs/2009_2014/documents/sede/dv/sede012313factsheetsahel_sede012313factsheetsahel_en.pdf (fecha de consulta: 2 de mayo de 2013); y «The European Commission's response to the food crisis and long-term food insecurity in the Sahel region of Africa», MEMO 12/215, Bruselas, 23 de marzo de 2012. 
las fases previas y posteriores a la detección de una situación de crisis-. Conjugando ambos textos, el procedimiento se estructura en tres fases: $a$ ) inicial - que requiere el análisis previo de la situación, tanto por órganos de la UE como por los propios Estados miembros—; $b$ ) intermedia — de creación de la misión a través de un conjunto de actos relativos a la adopción del concepto de gestión de crisis, la aprobación de la decisión, etc.—, y c) final de ejecución -que incluye, entre otros, la elaboración de los estatutos de las fuerza/personal con los terceros Estados participantes o el Estado receptor; la aprobación del plan de operaciones, la creación del comité de contribuyentes, etcétera-.

La flexibilidad también preside este procedimiento no reglado, en función de las circunstancias de cada situación de crisis analizada. Ello ha permitido el desarrollo de una variada tipología de misiones, civiles, militares o mixtas, para actuar tanto en situaciones de conflicto que requieren una previa pacificación, como en situaciones de posconflicto, una vez asentadas unas condiciones mínimas de seguridad. En función del tipo de misión, pueden variar los protocolos de actuación y la adopción de los documentos requeridos durante las diversas fases. Así pues, este proceso no deja de ser un condicionante que, unido a otros factores internos o externos, puede lastrar una adecuada y ágil respuesta de la UE ante la aparición de una crisis concreta.

Igualmente, el factor tiempo condiciona las tres fases de este procedimiento. La práctica de la UE ha demostrado que una respuesta ágil y rápida a la situación de crisis está siempre condicionada por diversos factores, externos o internos, formados a su vez por un conjunto variado de obstáculos o condicionantes. Así, en el procedimiento de creación de una misión, los factores internos son los clásicos: falta de experiencia, problemas de financiación, o problemas logísticos relacionados con la falta de medios adecuados para responder a una crisis concreta. Por ejemplo, los problemas económicos derivados de la falta de previsión, la dificultad de coordinación entre los Estados participantes y la gestión de los costes comunes en las misiones militares, solventados en mayor medida a partir del 2004 con la creación del mecanismo ATHENA. También los problemas logísticos, como la falta de ordenadores o material de oficina esencial para la ejecución de las tareas de las misiones PRÓXIMA (2003) y EUPAT (2005) en Macedonia. Igualmente, la falta de acuerdo y voluntad política de los Estados participantes es un factor interno decisivo en ocasiones en el lento despliegue de las misiones, como en la misión EUFOR Chad/RCA (2008). En todo caso, este tipo de condicionantes se han solventado, en general, sin mayores dificultades, permitiendo una respuesta rápida y adecuada a la crisis planteada.

Los factores externos, en cambio, son impredecibles y, mayormente, de tipo político, como la victoria de Hamas en las elecciones palestinas, causa de la inicial ejecución vacilante de la misión EUPOL COPSS (2006); o la inestabilidad política en Guinea-Bissau, que dificultó durante varios meses la planificación sobre el terreno de la operación de reforma del sector de la seguridad (2008). Este tipo de condicionantes sí han supuesto en más de una ocasión que la respuesta de la UE se retrasara considerablemente en el tiempo. 
Finalmente, la UE ha afrontado también situaciones con problemas más específicos y jurídicamente complejos que han condicionado el despliegue de una operación. Así sucedió con la declaración de independencia de Kosovo, que tuvo como consecuencia que la misión EULEX Kosovo (2008) entrara en una fase de stand by durante un periodo de diez meses.

Aun así, la complejidad del sistema institucional y procedimental para la creación de las misiones de paz no han impedido, en general, una ejecución de las tareas encomendadas por las decisiones de creación de las misiones en el tiempo debido, gracias también a los mecanismos de flexibilidad incorporados.

\title{
RESUMEN
} EL FACTOR TIEMPO EN EL PROCESO DE PLANIFICACIÓN, CREACIÓN
Y DESPLIEGUE DE LAS MISIONES DE PAZ DE LA UNIÓN EUROPEA

Las misiones de paz de la UE se han desarrollado a través de un procedimiento no reglado, dotado de una gran flexibilidad y vinculado al factor tiempo. Ambos elementos ponen de manifiesto la existencia de diversos condicionantes que pueden dificultar el desarrollo de estas misiones en el tiempo debido.

Palabras clave: Misiones de paz de la UE, Planificación, creación y desarrollo, Factor tiempo.

\section{ABSTRACT \\ THE TIME FACTOR IN THE PLANNING, CREATION AND DEPLOYMENT OF EUROPEAN UNION PEACEKEEPING MISSIONS}

EU peacekeeping missions have been developed through a non-regulated process characterized by great flexibility and closely linked to the time factor. Inherent in these features are various factors that may hinder the timely implementation of these missions.

Keywords: EU Peacekeeping, Planning, creation and development, Time factor.

\author{
RÉSUMÉ \\ LE FACTEUR TEMPS DANS LA PLANIFICATION, LA CRÉATION \\ ET LE DÉPLOIEMENT DES MISSIONS DE PAIX DE L'UNION EUROPÉENNE
}

Les missions de maintien de la paix de l'UE ont été développées par un processus non réglementé, très flexible et lié au facteur temps. Ces deux éléments révèlent l'existence de diverses conditions qui peuvent entraver le déroulement de ces missions en temps voulu.

Mots-clés: missions de maintien de la paix de l'UE, planification de la procédure, création et développement, facteur temps. 